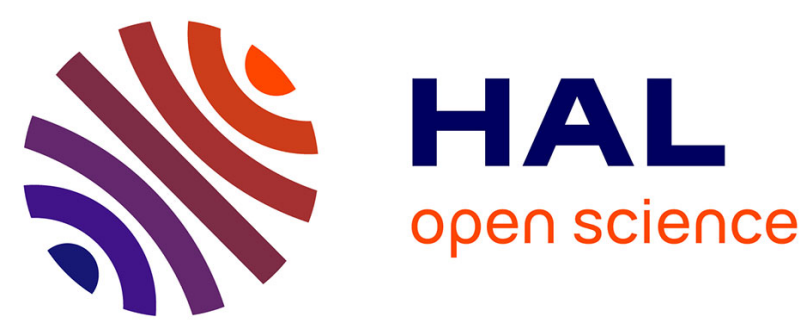

\title{
Experimental study of air-water two-phase flow pattern evolution in a mini tube: Influence of tube orientation with respect to gravity
}

Salim Zeguai, Salah Chikh, Lounès Tadrist

\section{- To cite this version:}

Salim Zeguai, Salah Chikh, Lounès Tadrist. Experimental study of air-water two-phase flow pattern evolution in a mini tube: Influence of tube orientation with respect to gravity. International Journal of Multiphase Flow, 2020, 132, pp.103413. 10.1016/j.ijmultiphaseflow.2020.103413 . hal-03194140

\author{
HAL Id: hal-03194140 \\ https://hal.science/hal-03194140
}

Submitted on 9 Apr 2021

HAL is a multi-disciplinary open access archive for the deposit and dissemination of scientific research documents, whether they are published or not. The documents may come from teaching and research institutions in France or abroad, or from public or private research centers.
L'archive ouverte pluridisciplinaire HAL, est destinée au dépôt et à la diffusion de documents scientifiques de niveau recherche, publiés ou non, émanant des établissements d'enseignement et de recherche français ou étrangers, des laboratoires publics ou privés. 


\title{
Experimental Study of Air-Water Two-Phase Flow Pattern Evolution in a Mini tube: Influence of Tube Orientation with Respect to Gravity
}

\author{
Salim Zeguai ${ }^{1,3}$, Salah Chikh ${ }^{2 *}$, Lounès Tadrist $^{3}$ \\ ${ }^{1}$ Yahia Farès University, LMP2M Laboratory, Ain d'heb, Médéa, Algeria \\ ${ }^{2}$ USTHB, Faculty of Mechanical and Process Engineering, LTPMP, Alger, Algeria \\ ${ }^{3}$ Aix-Marseille Université, CNRS, Laboratoire IUSTI, UMR 7343, Marseille, France
}

\begin{abstract}
The evolution of two-phase flow patterns is investigated experimentally in a $1500 \mathrm{~mm}$ long capillary tube of $3 \mathrm{~mm}$ inner diameter with different orientations with respect to gravity. The flow patterns are recorded with a fast camera (1000 fps) at two locations along the tube under the same operating conditions. The first is close to the inlet zone at $\mathrm{L} / \mathrm{D}=10$ and the second is far downstream at $\mathrm{L} / \mathrm{D}=420$. Co-flowing configurations downward and upward are considered where air is injected through a nozzle of $110 \mu \mathrm{m}$ of inner diameter and centered on the tube axis. Unlike many existing studies in the literature, the present work explores ranges of small superficial velocities of the two fluids, from $0.78 \times 10^{-3} \mathrm{~m} / \mathrm{s}$ to $79 \times 10^{-3} \mathrm{~m} / \mathrm{s}$ for the liquid phase and from $2.3 \times 10^{-3} \mathrm{~m} / \mathrm{s}$ to $3.54 \mathrm{~m} / \mathrm{s}$ for the gas phase, in order to deal with smooth interfaces. The experiments show that the flow patterns are very sensitive to inlet conditions. Although, the superficial velocities considered are very small, several two-phase flow patterns are visualized namely bubbly flow, slug flow, unstable annular and annular flow. In the upward flow, the annular pattern is unstable, while for the downward flow, the bubbly pattern is difficult to obtain. Phenomena like coalescence and breakup yield to the evolution of the flow pattern from the entrance of the tube to the downstream location. The visualizations highlight also that certain flow patterns evolve from one structure to another along the tube from the location $\mathrm{L} / \mathrm{D}=10$ to $\mathrm{L} / \mathrm{D}=420$. Furthermore, the two-phase flow maps are drawn
\end{abstract}


and the effect of gravity on the flow maps as well as on the flow pattern transitions is discussed.

Keywords: Two phase flow patterns, flow visualization, flow pattern evolution, vertical twophase flow, gravity influence.

\section{Nomenclature}

D diameter of test tube $[\mathrm{m}]$

$\mathrm{d}_{\mathrm{n}} \quad$ Needle diameter $[\mathrm{m}]$

$\mathrm{F}_{\mathrm{A}} \quad$ Buoyancy force $[\mathrm{N}]$

$\mathrm{F}_{\mu \mathrm{G}} \quad$ shear force $[\mathrm{N}]$

$\mathrm{L} \quad$ Length of the tube $[\mathrm{m}]$

$\operatorname{Re}_{\mathrm{GS}}$ Reynolds number of gas

$\operatorname{Re}_{\mathrm{LS}}$ Reynolds number of liquid

$\mathrm{S}_{\mathrm{LG}} \quad$ Interfacial surface $\left[\mathrm{m}^{2}\right]$

$\mathrm{U}_{\mathrm{GS}}$ gas superficial velocity $\left[\mathrm{m} \cdot \mathrm{s}^{-1}\right]$

$\mathrm{U}_{\mathrm{LS}} \quad$ liquid superficial velocity $\left[\mathrm{m} \cdot \mathrm{s}^{-1}\right]$

\section{Greek symbols}

$\rho_{\mathrm{G}} \quad$ gas density $=1.204\left[\mathrm{~kg} \cdot \mathrm{m}^{-3}\right]$

$\rho_{\mathrm{L}} \quad$ liquid density $=1000\left[\mathrm{~kg} \cdot \mathrm{m}^{-3}\right]$

$\mu_{\mathrm{G}} \quad$ dynamic viscosity of gas $=1.8 \times 10^{-5}\left[\mathrm{~kg} \cdot \mathrm{m}^{-1} \mathrm{~s}^{-1}\right]$

$\mu_{\mathrm{L}} \quad$ dynamic viscosity of liquid $=10^{-3}\left[\mathrm{~kg} \cdot \mathrm{m}^{-1} \mathrm{~s}^{-1}\right]$

$\sigma \quad$ surface tension $=0.073 \mathrm{~N} \cdot \mathrm{m}^{-1}$ 


\section{Introduction}

Research on two-phase flow has expanded considerably in recent decades and monumental progress is expected to contribute to the understanding of these complex flows. In many industrial applications, these types of flows are encountered, and a better understanding of the flow patterns would help optimize heat and mass transfer in several processes or for example the transport of oil and gas in the petroleum industry.

Phase distribution plays an important role in hydrodynamics and transport phenomena in two-phase flow in ducts. Pressure drop, heat and mass transfer and flow stability are very sensitive to the morphological structure of the flow. In capillary tubes, the interaction between phases and the walls of the tube become important and can thus modify the twophase flow compared to conventional tubes. Many investigations have been carried out over the last decade in order to better understand the behavior of these two-phase flows as confinement becomes more and more important.

A literature survey is conducted to review the works on two-phase flow in small pipes. We will focalize on the studies of adiabatic two-phase gas-liquid flow in circular small tubes.

Generally, experimental data are used to provide two-phase flow maps. However, the limits and transitions from one flow pattern to another are not well established and there is no consensus about transition lines when it comes to duct size of millimeter or sub-millimeter scale. Several parameters related to inlet conditions as well as the tube diameter can affect the flow pattern. Thus, a rigorous control of the flow rate of each phase and the way they are introduced into the test tube can help obtaining the desired flow pattern.

Investigations on adiabatic flow in circular tubes of small diameter have been carried out for gas-liquid flow in upward and downward directions under different geometrical configurations and operating conditions. Among the most well-known works we may cite those of Sugawara et al., 1967; Barnea et al., 1983; Biswas and Greenfield, 1985; Hijikata et al., 1985; Fukano et al., 1990; Kariyasaki et al., 1991; Kariyasaki and Fukano, 1992; Galbiati 
and Andreini, 1992; Fukano and Kariyasaki, 1993; Wölk et al., 2000; Chen et al., 2002; Ide et al., 2007 and Milan et al., 2013. Although several studies were conducted, there is still a need for further investigations and for supplemental information. In the following, we report on studies in open literature that considered air and water as working fluids. Tables 1 and 2 summarize the various works done to plot dimensional maps for air-water adiabatic flow in micro/mini glass tubes. We outline the influence of the tube diameter on two-phase flow patterns, the inlet conditions and how the two phases are brought to the test tube, the operating conditions and the orientation with regard to gravity.

Different geometric configurations were used for conveying the gas-liquid mixture. Some authors mixed the liquid and gas phases in a chamber before introduction into the test tube (Fukano and Kariyasaki, 1993); others used an expansion chamber for the liquid before mixing with the gas phase (Chen et al., 2002; Serizawa et al., 2002). This mixing chamber was sometimes filled with a porous medium to intensify mixing (Zhao and Bi, 2001). Shao et al., 2008 and Biswas and Greenfield, 1985, used T or Y junctions that bring the phases into a mixing chamber or directly in the test tube. Chen et al., 2002 and Amador et al., 2004, provided the contact between phases in the test tube by carrying the gaseous phase through an injection needle at the channel center and the liquid phase in annular cross-section around the needle.

For the vertical orientation with an upward flow, several maps were proposed in the literature for tubes with small diameter (Barnea et al., 1983; Wölk et al., 2000; Kariyasaki et al., 1992; Fukano and Kariyasaki, 1993; Mishima and Hibiki, 1996; Ide et al, 2007). Figure 1 illustrates the published flow maps for tube diameter between 2 and $6 \mathrm{~mm}$. The analysis of these maps let us first highlight the effect of tube diameter on flow patterns and the transition boundaries. Kariyasaki et al., 1992, considered two diameters: $2.05 \mathrm{~mm}$ and $4.08 \mathrm{~mm}$. Figure 1 shows the main differences between the transition lines of the two tubes. At first glance, we see a shift of the transition lines of bubbly flow to the intermittent flow at lower superficial 
velocities of gas and liquid. A decrease of the tube size remarkably shifts the transition line of the annular flow downwardly to smaller superficial velocity of the liquid phase. However, there is little effect of the tube size on the transition from slug flow to annular flow at higher gas velocities.

The effect of the channel size on the extension of the zone of bubbly flow pattern to smaller liquid superficial velocities could be attributed to the dominance of the buoyancy force with regard to the surface tension force in higher tube diameter. Bubbles formed are easily detached thereby producing a dispersed bubbly flow. At higher gas and liquid superficial velocities, inertia dominates and subsequently assisted by buoyancy. Thus, the transition to annular flow is not significantly affected by the tube diameter.

A comparison between the maps of Barnea et al., 1983, for a tube of $4 \mathrm{~mm}$ in diameter and that of Kariyasaki et al., 1992, for a tube diameter of $4.08 \mathrm{~mm}$, reveals similarities for certain transition lines and differences for others. Indeed, different inlet conditions could have been used by the authors. Barnea et al., 1983, gave little information on metrology and geometric configurations used to produce the gas-liquid mixture and on the position along the tube where they visualized the flow pattern. In the work of Kariyasaki et al., 1992, the two phases are introduced into a mixing chamber. The liquid phase flows upward in the axial direction of the tube and the gas along the perpendicular direction. This results in different flow patterns (bubbly, slug, annular, etc...). So, the transition lines may change from one map to another according also to the viewing position along the tube.

Unlike the upward flow, for the vertical orientation with a downward flow in mini or micro- tubes, the literature survey reveals the existence of a very limited number of studies (Biswas and Greenfield, 1985; Galbiati and Andreini, 1992; Fukano and Kariyasaki, 1993; Ide et al., 2007; Milan et al., 2013). Figure 2 shows the maps reported in the literature for a tube with diameter between 1 and $8.8 \mathrm{~mm}$. Overall, all the maps look like and show the same flow patterns: bubbly, slug and annular flow except the map of Biswas and Greenfield, 1985, 
which shows different transition lines. Nevertheless, in the other maps, transition zones may differ from authors to others according to the pipe diameter. When the tube size decreases, a shift of the transition lines (dispersed bubbly or bubbly/slug, slug/annular) to small apparent velocities of the liquid is observed and the zone of the annular flow pattern shrinks.

Moreover, according to the open literature (Fukano and Kariyasaki, 1993; Hassan et al., 2005; Ide et al., 2007; Bhagwat and Ghajar, 2012), the gravity effect i.e. tube orientation is shown to play a non-negligible role on the phase distribution in small diameter pipes. However, attention was not focused particularly on the effect of gravity, but just as one parameter among others. So, it is therefore an influencing parameter which remains so far not sufficiently developed and not well documented in mini and micro channels (Chinnov and Kabov, 2006 ; Saisorn and Wongwises, 2008 ; Shao et al., 2009 ).

Due to the limited number of studies dedicated to upward and downward two-phase flow in vertical tubes of small diameter as well as the little information given by certain authors with regard to inlet conditions and the visualization location along the tube, it is difficult to draw any concise conclusion on the effect of mixing conditions, fluid properties or any other control parameter on two-phase flow patterns and their transitions. To our best knowledge, no study reported on the evolution of the two-phase flow pattern along the mini or micro-channel neither in upward nor in downward flow direction. The transition limits depend on tube orientation and they change from one author to another. In particular, there is an entanglement of these transitions curves and it is difficult to interpret the maps experimentally and empirically established. In conclusion, we may say that all authors obtained the main structures (bubbly, slug, annular) for different orientations of the two-phase flow with respect to gravity. However, the intermediate patterns (breakup slug/annular) depend on the flow orientation. Therefore, further investigations are still needed to complete information. 
The purpose of this study is to visualize and analyze two-phase flow patterns in a long capillary tube for vertical upward and downward flow. In order to highlight the evolution of the flow patterns, two locations are considered along the tube. The first is at the inlet of the test tube at $\mathrm{L} / \mathrm{D}=10$ where the two-phase flow is generated, the second is far downstream at $\mathrm{L} / \mathrm{D}=420$.

The different works reported in the open literature explored high superficial velocities from $6 \times 10^{-3} \mathrm{~m} / \mathrm{s}$ to $10 \mathrm{~m} / \mathrm{s}$ for the liquid phase and from $50 \times 10^{-3} \mathrm{~m} / \mathrm{s}$ to $100 \mathrm{~m} / \mathrm{s}$ for the gas phase. While, we investigate very small superficial velocities from $0.78 \times 10^{-3} \mathrm{~m} / \mathrm{s}$ to $79 \times 10^{-3}$ $\mathrm{m} / \mathrm{s}$ for the liquid phase and from $2.3 \times 10^{-3} \mathrm{~m} / \mathrm{s}$ to $3.54 \mathrm{~m} / \mathrm{s}$ for the gas phase in order to deal with smooth interfaces under laminar flow conditions.

Visualizations are recorded with a fast camera with $1000 \mathrm{fps}$ at both locations. Several flow patterns are highlighted, their evolution along the tube is documented and the two-phase flow maps are drawn for both locations. A comparison of the flow maps for different orientations is carried out and the effect of gravity is analyzed.

\section{Experimental apparatus and operating conditions}

The experimental device to perform air-water two-phase flow with the best possible controlled inlet conditions has been detailed in a previous paper (Zeguai et al., 2013). Hereafter a brief description is given. We mainly remind the main components used and the running apparatus for upward and downward two-phase flow. It consists essentially of the test tube adjustable with regard to gravity from $0^{\circ}$ to $180^{\circ}$, surrounded by several elements to convey the liquid and gas phases and to master the flow rates. Figure 3 shows a schematic of the apparatus. The realized glass tube (Fig.4) consists of an expansion chamber for water with a convergent shape and a length of $210 \mathrm{~mm}$ prior to a circular pipe of $3 \mathrm{~mm}$ inner diameter and $1500 \mathrm{~mm}$ length. The interior volume of the expansion chamber is completely filled with distilled water. This measurement cell is designed to be waterproof in the range of relative 
pressures from 1 to 15 bars. The air is injected axially under pressure in the test tube by a needle of circular cross section of $110 \mu \mathrm{m}$ inner diameter $d_{n}$ and $70 \mathrm{~mm}$ in length from Hamilton Company.

Prior to experiments, the measurement cell is cleaned with alcohol to remove any impurities and dried with dry air. The liquid loop is filled with distilled water by means of a gear pump from a reservoir at atmospheric pressure and room temperature of $23^{\circ} \mathrm{C}$. The air trapped inside the expansion chamber is easily discharged through the purge system. The filling time of the distilled water loop depends on the value of the selected setpoint for the flow rate. This latter is measured by a flowmeter, Bronkhorst High-Tech BV, in a range of 2 $\mathrm{g} / \mathrm{h}$ to $2000 \mathrm{~g} / \mathrm{h}$ with an uncertainty of $0.2 \%$. It is controlled by a PC with dedicated software, FlowDDE, Flowview, and Flowplot of Bronkhorst High-Tech BV company.

For a given setpoint of liquid flow rate, the pump gradually produces sufficient pressure until the flow rate supplied by the pump (measured rate) converges to the setpoint value. Once convergence is achieved between the setpoint and the measured value, water flow rate is kept constant for the desired operating conditions. Then, we proceed to the injection of the gas through the needle. The air is supplied from an autonomous compressor (Powerlite AKHL1230E) to avoid any possible external disturbance. The compressor supplies air at a pressure ranging from 1 to 34 bars adjustable to the room temperature of $23^{\circ} \mathrm{C}$. The air is filtered before passing through the gas controller flowmeter (Bronkhorst High-Tech BV). As for water, this flowmeter provides an accurate measurement of air flow rate regardless of fluctuations in temperature and pressure with an accuracy of $1 \%$. This instrument is equipped with a control system managed by the software (Flowtune, FlowDDE, Flowview and Flowplot) of the company Bronkhorst High-Tech BV. To cover a wide range of air flow rate $\left(14 \times 10^{-4} \mathrm{mln} / \mathrm{min}\right.$ up to $\left.1500 \mathrm{mln} / \mathrm{min}\right)$ three controller flowmeters are used. The first covers the range $14 \times 10^{-4} \mathrm{ml} / \mathrm{min}$ to $5 \mathrm{ml} / \mathrm{min}$, the second from $1.6 \mathrm{mln} / \mathrm{min}$ to $200 \mathrm{mln} / \mathrm{min}$ and the third from $8 \mathrm{ml} / \mathrm{min}$ to $1500 \mathrm{ml} / \mathrm{min}$. The pressures at the inlet and the outlet of the test tube 
are measured with two differential pressure gages Sensym SCX100DN operating in a range of 0-100 $\mathrm{kPa}$ with a sensitivity of $7 \mathrm{~Pa} / \mu \mathrm{V}$. The uncertainty of the electrical device is $40 \mu \mathrm{V}$ which corresponds to $300 \mathrm{~Pa}$. The pressure gages are calibrated between 1 and $100 \mathrm{kPa}$ with a calibration unit DPI605 Druck 20 bar. A Hewlett Packard HP 34970A data acquisition system is used for acquiring instantaneous pressure data at the inlet and the outlet of the tube and controlled by BenchLink Agilent software. Visualizations of two-phase flow patterns in the mixing zone (inlet region at $\mathrm{L} / \mathrm{D}=10$ ) and downstream at $\mathrm{L} / \mathrm{D}=420$ are made by means of a high speed camera (Ultima-FASTCAM 1024) with a resolution of $1024 \times 512$ pixels, a zoom of 150 times, a speed of $1000 \mathrm{fps}$ and an aperture of $1 / 10000 \mathrm{~s}$. The camera is mounted on a three-dimensional displacement table with micrometric precision for positioning and calibration of images taken by the camera. The light used for viewing is provided by an adjustable cold light source (Sc Dedeolight) in the test area. An optical diffuser is interposed between the cold lamp and the displayed test area, so that the light is uniform over the entire field of view of the high-speed camera. In order to minimize optical distortion due to the circular shape of the test tube, an optical correction chamber (iso-index chamber) of rectangular shape (42 mm $37 \mathrm{~mm} \times 167 \mathrm{~mm}$ ) of glass is placed around the display area. This optical correction chamber is filled with Triton X-100 with a refractive index of 1.473 nearly equal to the refractive index of the glass 1.5 .

\section{Results and discussion}

Before presenting our results, it is worth noting that in most of the published experimental works carried out to draw two-phase flow maps, the authors operated in the following ranges of superficial velocities from $50 \times 10^{-3} \mathrm{~m} / \mathrm{s}$ to $100 \mathrm{~m} / \mathrm{s}$ for the gas phase and from $6 \times 10^{-3} \mathrm{~m} / \mathrm{s}$ to $10 \mathrm{~m} / \mathrm{s}$ for the liquid phase (see Fig. 1 and Fig. 2). With the high superficial velocity ranges considered by many authors, the flow can lead to highly disturbed interfaces. Therefore, in order to obtain laminar flow conditions and smooth interfaces, we investigated 
rather small superficial velocities from $2.3 \times 10^{-3} \mathrm{~m} / \mathrm{s}$ to $3.54 \mathrm{~m} / \mathrm{s}$ for the gas phase and from $0.78 \times 10^{-3} \mathrm{~m} / \mathrm{s}$ to $79 \times 10^{-3} \mathrm{~m} / \mathrm{s}$ for the liquid phase. Reynolds numbers $\left(\operatorname{Re}_{\mathrm{LS}}=\rho_{\mathrm{L}} \mathrm{U}_{\mathrm{LS}} \mathrm{D} / \mu_{\mathrm{L}}, \operatorname{Re}_{\mathrm{GS}}\right.$ $=\rho_{\mathrm{G}} \mathrm{U}_{\mathrm{GS}} \mathrm{D} / \mu_{\mathrm{G}}$ ) corresponding to these superficial velocities vary from 0.2 to 710 for the gas phase and from 2.3 to 230 for the liquid phase, while for the majority of flow regimes reported in the literature the Reynolds numbers vary from 20 to 30,000 for the liquid phase and from 10 to 20,000 for the gas phase. If we extrapolate the flow maps proposed by several authors to our investigated ranges of superficial velocities, then this would lead to slug flow for the upward flow configuration and to either slug or annular flow for the downward case. However, our explorations allow highlighting other patterns namely several morphologies of bubbly flow, slug and annular flow, which may evolve along the tube according to the operating conditions. Visualizations are recorded in two locations along the tube. At the entrance region at $L / D=10$ where the two phases are brought in contact and far downstream at $\mathrm{L} / \mathrm{D}=420$. In the next section, visualization of flow patterns in both locations under different operating conditions are presented and discussed in detail.

\subsection{Visualization of two-phase flow patterns}

To show the influence of involved forces on the flow patterns, three cases will be discussed in this section: small liquid superficial velocity $\left(U_{L S}=0.78 \times 10^{-3} \mathrm{~m} / \mathrm{s}, \operatorname{Re}_{\mathrm{LS}}=2.3\right.$, moderate liquid superficial velocity $\left(\mathrm{U}_{\mathrm{LS}}=29 \times 10^{-3} \mathrm{~m} / \mathrm{s}, \mathrm{Re}_{\mathrm{LS}}=88\right)$ and high liquid superficial velocity $\left(\mathrm{U}_{\mathrm{LS}}=59 \times 10^{-3} \mathrm{~m} / \mathrm{s}, \mathrm{Re}_{\mathrm{LS}}=176\right)$, while the superficial gas velocity is varied within the range from $3.8 \times 10^{-3} \mathrm{~m} / \mathrm{s} \quad\left(\operatorname{Re}_{\mathrm{GS}}=0.2\right)$ to $3.53 \mathrm{~m} / \mathrm{s}\left(\operatorname{Re}_{\mathrm{GS}}=710\right)$. Examination of competition between the involved forces and their influence on flow morphology will be based on the operating conditions (superficial velocities of water and air). These flow patterns will be discussed, and qualitative interpretation will be presented by introducing the forces playing a role in the flow patterns.

\subsubsection{Upward Flow}


Three basic flow patterns could be observed: dispersed bubbly, slug and unstable annular flow. However, unlike reported in previous experimental studies (Fukano and Kariyasaki, 1993; Ide et al. 2007) intermediate structures like bubbly-slug, slug-annular and breakup slug/annular clearly appeared during transitions from a main structure to another.

\section{a/ Small liquid superficial velocity $\left(U_{L S}=0.78 \times 10^{-3} \mathrm{~m} / \mathrm{s}, \operatorname{Re}_{L S}=2.3\right)$}

At very low gas superficial velocity $\mathrm{U}_{\mathrm{GS}}=3.8 \times 10^{-3} \mathrm{~m} / \mathrm{s}$, we observe a transition pattern between bubbly and slug flow at the location $\mathrm{L} / \mathrm{D}=10$ as shown in Fig.5.a.1. Because of the very small superficial velocity of water, $U_{L S}=0.78 \times 10^{-3} \mathrm{~m} / \mathrm{s}$, the shear forces $\left(F_{\mu G}=\mu_{L}\left(U_{G S}-\right.\right.$ $\left.\left.\mathrm{U}_{\mathrm{LS}}\right) \mathrm{S}_{\mathrm{LG}} / \mathrm{D}\right)$ are very high and the buoyancy forces are important $\left(\mathrm{F}_{\mathrm{A}}=\rho_{\mathrm{L}} g \mathrm{~V}_{\mathrm{G}}\right)$. There is formation of elongated bubbles separated by several discrete bubbles of very small size glued to each other and moving up slowly along the tube. These elongated bubbles are either generated at the exit of the air injection nozzle or are the result of coalescence of the small bubbles. This pattern evolves to a clear slug flow at the location $\mathrm{L} / \mathrm{D}=420$ as displayed in Fig.5.b.1.

At a higher superficial gas velocity, $\mathrm{U}_{\mathrm{GS}}=8 \times 10^{-3} \mathrm{~m} / \mathrm{s}$, the slug flow pattern is established where the elongated bubble develops at the injection nozzle. The size of elongated bubbles is very little affected by the increase of gas velocity. By increasing the gas superficial velocity to $\mathrm{U}_{\mathrm{GS}}=47 \times 10^{-3} \mathrm{~m} / \mathrm{s}$ (Fig.5.a3), fine microbubbles are formed at the exit of the gas injection nozzle. These microbubbles are generated because of the significant absolute velocity of the gas in the needle (i.e $u_{G}=35 \mathrm{~m} / \mathrm{s}, \operatorname{Re}_{\mathrm{G}}=\rho_{\mathrm{G}} \mathrm{u}_{\mathrm{G}} \mathrm{d}_{\mathrm{n}} / \mu_{\mathrm{G}}=258$ ) injected in an upward liquid flow with a small superficial velocity. Subsequently, a bubble expands at the nozzle exit to form an elongated bubble taking with it the microbubbles. This process is repeated again on a periodic basis. The concentration of microbubbles between the slugs increases with the progressive increase in the superficial air velocity until the liquid plugs disappear and give way to microbubbles at $\mathrm{U}_{\mathrm{GS}}=146 \times 10^{-3} \mathrm{~m} / \mathrm{s}$ (Fig.5.a.4). This flow morphology (Figs.5 (a.2)-(a.4)) 
lasts until the superficial velocity of air reaches a value of $165 \times 10^{-3} \mathrm{~m} / \mathrm{s}$ at which the unstable annular flow sets up. The slug flow pattern keeps along the tube to the location $L / D=420$ and shows smooth interfaces (Figs.5 (b.1)-(b.4)). For superficial gas velocities sufficiently high (Figs.5 (a.5) and (a.6)), an unstable flow occurs which is characterized by a distorted liquidgas interface in a zone where the two phases are strongly agitated preventing the annular structure to establish. This agitation is due to upward motion of the gas phase and successive quick and short motions (falling and raising) of the liquid film thereby producing a counter flow and co-current flow respectively. Thus, an extremely rapid rupture of unstable annular structure downstream of the injection nozzle is observed. Simultaneously there is formation of gas microbubbles. It is a complex mechanism of atomization which is superposed on the formation of unstable annular structure.

At a superficial velocity of air $U_{G S}=778 \times 10^{-3} \mathrm{~m} / \mathrm{s}$, the unstable annular pattern at $\mathrm{L} / \mathrm{D}=10$ (Fig.5.a.6) evolves to a slug pattern at $\mathrm{L} / \mathrm{D}=420$ (Fig.5.b.6) due to breakup phenomenon. Indeed, visual examination helps to realize that the unstable annular flow undergoes periodic downward and upward rapid movements and breakup of liquid-gas interface (Fig.5.b.6), preventing the annular flow to settle. These falling and raising movements are defined in the literature as reversal flow typical to two-phase flow in vertical circular tubes. This phenomenon is characterized by a local accumulation of liquid in the entrance region $(\mathrm{L} / \mathrm{D}=$ 10) which is then pulsed by the gas injected at high velocity. Consequently, as illustrated in Fig.5.b.6, this phenomenon results from a duality between gravity inertia and shear effects. We observe for a very short period of time a reversal flow (Fig.5.b.6.1) with a downward liquid motion before the gas breakup and then followed by an upward liquid motion (Fig.5.b.6.2). Potentially, in this situation, the gas morphology changes from an annular pattern to a slug flow.

b/ Moderate liquid superficial velocity $\left(U_{L S}=29 \times 10^{-3} \mathrm{~m} / \mathrm{s}, \operatorname{Re}_{L S}=88\right)$ 
At low superficial gas velocity, $\mathrm{U}_{\mathrm{GS}}=3.8 \times 10^{-3} \mathrm{~m} / \mathrm{s}$, there is formation of a dispersed bubbly flow pattern in the entrance region $\mathrm{L} / \mathrm{D}=10$ (Fig. 6.a.1). These bubbles are small and of different sizes. Under these circumstances, the bubbles rise with higher velocity than the twophase flow velocity $\left(\mathrm{U}_{\text {bubble }}=0.171 \mathrm{~m} / \mathrm{s}, \mathrm{U}_{\mathrm{M}}=0.0328 \mathrm{~m} / \mathrm{s}\right)$. By increasing the gas superficial velocity to $\mathrm{U}_{\mathrm{GS}}=28 \times 10^{-3} \mathrm{~m} / \mathrm{s}$, the size of formed bubbles increases. The measured bubble velocity are slightly less than the previous case while the two-phase velocity is higher (Ububle $\left.=0.160 \mathrm{~m} / \mathrm{s}, \mathrm{U}_{\mathrm{M}}=0.056 \mathrm{~m} / \mathrm{s}\right)$. They form a regular chain of nearly spherical bubbles in helical motion (Fig.6.a.3). By further increasing $\mathrm{U}_{\mathrm{GS}}$ to $30 \mathrm{x} 10^{-3} \mathrm{~m} / \mathrm{s}$, we approach a transition bubblyslug pattern (Fig.6.a.4). The slug is formed at the needle exit or is the result of coalescence of several bubbles in this zone. Increasing gradually the gas velocity up to a value of $60 \times 10^{-3}$ $\mathrm{m} / \mathrm{s}$, then many slugs of relatively small size appear with fine satellite bubbles (Fig.6.a.5).

At a higher gas superficial velocity, $\mathrm{U}_{\mathrm{GS}}=106 \times 10^{-3} \mathrm{~m} / \mathrm{s}$, the slugs lengthen and break up in a disordered manner producing slugs and bubbles adhering to each other yielding a transition pattern (Fig.6.a.6). This latter is an intermediate structure between slug and annular flow pattern typical to vertical flow. For a sufficiently high superficial velocity of the gas phase, $\mathrm{U}_{\mathrm{GS}}=212 \times 10^{-3} \mathrm{~m} / \mathrm{s}$, an unstable annular flow develops (Fig.6.a.7). This situation is similar to the previous case with high shear and dominates buoyancy (Fig.5.a.5).

Downstream at $\mathrm{L} / \mathrm{D}=420$, several structures appear successively with increasing the superficial velocity of the gas phase (Fig.6.b). At small value of $U_{\mathrm{GS}}=3.8 \times 10^{-3} \mathrm{~m} / \mathrm{s}$, bubbles tend to cluster in three and move up along the axis of the tube (Fig.6.b.1). As $U_{G S}$ is increased to $24 \times 10^{-3} \mathrm{~m} / \mathrm{s}$ (Fig.6.b.2), bubbles get larger in size and form a bubble stream in a helical movement like a screw motion. This movement in which the bubble is entrained by a combination of a translation and a rotation of the liquid phase, occurs under particular operating conditions.-Then, as superficial velocity of air get larger, small bubbles are dispersed over the entire cross section of the tube and glued behind a slug; thereby forming a 
dispersed bubbly-slug pattern. The elongated bubble is due to coalescence of small bubbles. The slugs are relatively long with uniform front and a regular very thin liquid film throughout. In liquid plugs, we see small agitated bubbles. Transitions from bubbly to slug and from slug to annular flow are very clear.

\section{c/ High liquid superficial velocity $\left(U_{L S}=59 \times 10^{-3} \mathrm{~m} / \mathrm{s}, \operatorname{Re}_{L S}=176\right)$}

At higher liquid superficial velocity, $\mathrm{U}_{\mathrm{LS}}=59 \times 10^{-3} \mathrm{~m} / \mathrm{s}$, the main structures (dispersed bubbly, slug and unstable annular) as well as transition patterns (bubbly-slug and slug-annular) are visualized like the case of moderate liquid velocity but with some behavioral differences. At very low superficial velocity of gas, the dispersed bubbles formed in the mixing zone at $\mathrm{L} / \mathrm{D}=$ 10 have a much smaller size, and this is probably due to reduced shear forces and an increase of liquid inertia with the increase in water flow rate (Fig.7.a.1). By increasing the gas flowrate, the size of bubbles increases along the tube as a bubble train (Fig.7 (a.2)-(a.4)) until the emergence of the bubbly-slug structure (Fig.7.a.5) at $\mathrm{U}_{\mathrm{GS}}=61 \times 10^{-3} \mathrm{~m} / \mathrm{s}$. This bubbly-slug transition structure occurs in the same manner as the previous case, but with more gas bubbles behind the slug. This pattern transits directly to a highly disordered bubbly-slug structure (Fig.7.a.6) before reaching the unstable annular flow pattern (Fig.7.a7, a.8). In this case of low shear, the slug flow pattern is not visualized. In the downstream region, $L / D=420$, by changing the gas velocity, similar flow patterns are observed like the case of moderate liquid velocity. Though, it should be noted that the annular structure was not visualized because high velocities have not been reached for safety reasons. Indeed, high gas flow rates generated by pressures greater than 15 bars have not been investigated for the sake of preservation of the experimental device.

\subsubsection{Downward flow}

For this configuration similar experiments were carried out. In what follows a description of the two-phase flow visualization is given for typical structures observed. Besides the main patterns, secondary structures clearly appear during the transition from a main structure to 
another, unlike the previous experimental study of Galbiati and Andreini, 1992, this is due to the operating conditions carefully controlled (gas and liquid flow rates), working fluids and the nozzle diameter.

\section{a/ Low liquid superficial velocity $\left(U_{L S}=0.78 \times 10^{-3} \mathrm{~m} / \mathrm{s}, \operatorname{Re}_{L}=2.3\right)$}

At very low gas superficial velocity, up to $7 \times 10^{-3} \mathrm{~m} / \mathrm{s}$, just a liquid flow is observed in the tube. The injected air through the nozzle forms small bubbles that are quickly evacuated up due to the dominant effect of buoyancy. The drag force is just not sufficient because of the very small liquid superficial velocity. When the gas superficial velocity takes values above $7 \times 10^{-3} \mathrm{~m} / \mathrm{s}$, a stable annular structure is visualized in the entrance region at $\mathrm{L} / \mathrm{D}=10$ (Fig.8.a.1) that lasts for higher gas velocities.

In the downstream region at $\mathrm{L} / \mathrm{D}=420$, the flow morphology presents elongated bubbles (slug flow) at small gas superficial velocity (Fig.8.b.1). This structure is characterized by elongated cylindrical gas bubbles with smooth interfaces. The front of gas slug is of rounded shape while its rear end is rather flat. Thus, the annular pattern observed at $\mathrm{L} / \mathrm{D}=10$ has evolved to a slug flow due the rupture of the liquid-gas interface probably due to capillary effect (Rayleigh plateau-instability). By increasing the gas velocity by small increments, the length of the liquid plug between two successive elongated bubbles reduces and the flow morphology tends progressively to an annular flow pattern (Fig.8 (b2)-(b4)). In this case the film thickness around the slug is reduced and the capillary instability is not able to develop.

\section{b/ Moderate liquid superficial velocity $\left(\mathrm{U}_{\mathrm{LS}}=2 \mathbf{2 9}_{\mathrm{x}} 10^{-3} \mathrm{~m} / \mathrm{s}, \mathrm{Re}_{\mathrm{L}}=\mathbf{8 8}\right)$}

For small gas superficial velocity, $U_{\mathrm{GS}}=3.8 \times 10^{-3} \mathrm{~m} / \mathrm{s}$ at moderate liquid superficial velocity, we visualize in the entrance region at $\mathrm{L} / \mathrm{D}=10$ the formation of a bubbly structure (Fig.9.a.1). The bubbles are large and spherical and occupy approximately the entire cross section of the tube. Despite, the buoyancy force which oriented upward, the bubbles move downward with a higher absolute velocity $\left(U_{\text {bubble }}=0.054 \mathrm{~m} / \mathrm{s}\right)$ than the two-phase mixture velocity $\left(U_{M}=0.033\right.$ $\mathrm{m} / \mathrm{s}$ ). This effect might be explained by the dominating shear force induced by the liquid 
phase on the bubble. When the velocity of the gas phase is increased at $U_{\mathrm{GS}}=17_{\mathrm{x}} 10^{-3} \mathrm{~m} / \mathrm{s}$, a bubble train is formed (Fig.9 (a.2)-(a.4)); then the size of bubbles increases and the distance between successive bubbles reduces due to buoyancy, to yield a bubbly/slug transition (Fig.9.a.5) and a slug pattern at $\mathrm{U}_{\mathrm{GS}}=47 \times 10^{-3} \mathrm{~m} / \mathrm{s}$ (Fig.9.a.6) accompanied by very fine satellite bubbles. With the gradual increase in the superficial velocity of gas, an intermediate pattern i.e. fractioned slug/annular sets up with intense concentration of microbubbles between the slugs (Fig.9.a.7). For gas velocity even higher $\left(\mathrm{U}_{\mathrm{GS}}=94 \times 10^{-3} \mathrm{~m} / \mathrm{s}\right)$, an unstable annular flow occurs, and it is characterized by breakup of the liquid-gas interface downstream of the injection nozzle. Consequently, there is formation of gas microbubbles as a result of the high velocity of the gas phase at the injection nozzle. It is a complex mechanism of atomization which is superimposed on the formation of unstable annular structure (Fig.9.a.8). By further increasing the gas superficial velocity, the rupture zone moves throughout our viewing window in the direction of flow until it completely disappears of view. In this situation, the annular pattern remains unstable because as we will see later a transition pattern slug-annular is visualized downstream of the pipe at $\mathrm{L} / \mathrm{D}=420$. When $\mathrm{U}_{\mathrm{GS}}$ becomes greater than $\mathrm{U}_{\mathrm{GS}}=99 \times 10^{-3} \mathrm{~m} / \mathrm{s}$, the stable annular flow takes place.

In the downstream region $(\mathrm{L} / \mathrm{D}=420)$, the bubbly flow pattern observed in the entrance region remains basically a bubbly pattern with some alteration in the bubble shape due to occasional coalescence and probably other effects like drag and confinement effects (Fig.9 (b.1)-(b.4)). At higher gas superficial velocity, the slug flow at $\mathrm{L} / \mathrm{D}=10$ evolves to a slug pattern with longer slugs. This could be a result of some coalescence that may be due to the more important buoyancy and a lower drag force (Fig.9 (b.5)-(b.6)). The transition breakup slug-annular flow and the unstable annular flow in the entrance region at $\mathrm{L} / \mathrm{D}=10$ evolve to a slug flow at L/D $=420$ (Fig.9 (b.7)-(b.8)) because of the breakup of the liquid-gas interface. At a sufficiently high superficial velocity of gas, the annular structure at $\mathrm{L} / \mathrm{D}=10$ 
becomes first a transition pattern slug-annular (Fig.9.b.9) before it evolves to an annular flow pattern at a velocity $\mathrm{U}_{\mathrm{GS}}=260 \times 10^{-3} \mathrm{~m} / \mathrm{s}$ (Fig.9.b.10).

\section{c/ High liquid superficial velocity $\left(U_{L S}=59 \times 10^{-3} \mathrm{~m} / \mathrm{s}, R_{L}=176\right)$}

With a high liquid superficial velocity, the shear is reduced because of the reduction of the velocity difference of two fluids at the interface, and thus helps the bubble formation in the entrance region particularly at small gas superficial velocity. Figures 10 (a.1)-(a.3)) show the bubble train at $\mathrm{L} / \mathrm{D}=10$ that evolves to a bubble bed pattern at $\mathrm{L} / \mathrm{D}=420$ for $\mathrm{U}_{\mathrm{GS}}=$ $3.8 \times 10^{-3} \mathrm{~m} / \mathrm{s}$ (Fig.10.b.1) or remains a bubbly flow (Fig.10.b.2) or presents an intermediate morphology with a bubbly-slug pattern at $\mathrm{U}_{\mathrm{GS}}=38 \times 10^{-3} \mathrm{~m} / \mathrm{s}$ (Fig.10.b3). When increasing the gas superficial velocity, a bubble foam pattern is seen with small size bubbles at $\mathrm{L} / \mathrm{D}=10$ (Fig.10.a.4 and a.5). This is due to shear force taking over the surface tension. This pattern evolves to a clear and organized slug pattern with few very fine satellite bubbles between the elongated gas slugs (Fig.10.b.4 and b.5). At $\mathrm{U}_{\mathrm{GS}}=90 \times 10^{-3} \mathrm{~m} / \mathrm{s}$, a mixture of bubble foam and slugs is observed (Fig.10.a.6) indicating the following transition to unstable annular flow pattern (Fig.10.a.7). These morphologies become a slug pattern and a transition pattern slugannular in the downstream region (Fig.10.b.6 and b.7). At a high superficial velocity of the gas phase $U_{\mathrm{GS}}=401 \times 10^{-3} \mathrm{~m} / \mathrm{s}$, the annular flow settles from the injection nozzle to the downstream zone (Fig.10.a.8 and b.8).

To summarize, the main patterns (dispersed bubbly, slug, unstable annular with atomized bubbles formed by atomization phenomenon) and transition patterns (dispersed bubbly/slug, breakup slug/annular) observed in the mixing zone are similar to those obtained far downstream at $(\mathrm{L} / \mathrm{D}=420)$, except for the breakup slug/annular transition pattern. This simplification is the result of a coalescence phenomenon produced between bubbles and slugs generating slugs at far from the entrance zone.

\subsection{Flow maps}


From all the obtained experimental results, both vertical upward and downward twophase flow maps are drawn in the two zones of interest $L / D=10$ and $L / D=420$ showing the different regimes according to superficial velocities of fluids. The flow regime maps are drawn on a linear scale to have a better view of information particularly at the transition lines. The main features of the flow patterns in each zone are highlighted. In addition to the maps of the vertical orientations, the case of horizontal orientation is also presented from a previous study (Zeguai et al., 2013). A comparison of the three flow maps is carried out and an interpretation is attempted by considering the main forces involved.

\subsubsection{Upward two-phase flow pattern}

Figure 11 shows the flow regime maps for the upward flow at locations $L / D=10$ and $\mathrm{L} / \mathrm{D}=420$. The curves represent the transition boundaries between different flow patterns. This representation does not allow a detailed description of the flow morphology since it does not give, for example for the dispersed bubbly flow, the size and distribution of bubbles that depend on the operating conditions.

We may mention first that the liquid superficial velocity has little influence on the transition curves since for a given gas velocity the transition lines are almost vertical on the plot. This is confirmed for both regions ( $\mathrm{L} / \mathrm{D}=10$ and 420$)$, except for the transition to the unstable annular flow pattern in the downstream region $(\mathrm{L} / \mathrm{D}=420)$ and the slight effect of the liquid superficial velocity in the range $U_{\mathrm{GS}}<0.05 \mathrm{~m} / \mathrm{s}$ and $\mathrm{U}_{\mathrm{LS}}<0.02 \mathrm{~m} / \mathrm{s}$ as illustrated in Fig. 11 . With regard to flow pattern evolution along the tube, we may note that the boundary of the dispersed bubbly flow at $\mathrm{L} / \mathrm{D}=10$ shifts to smaller superficial gas velocities at $\mathrm{L} / \mathrm{D}=420$. The dispersed flow pattern evolves to bubbly/slug one. This might be explained by the coalescence between small bubbles, which occurs along the tube; therefore, yielding big bubbles or slugs (see Fig. 7). Furthermore, the slug-annular and the unstable annular flow pattern in the entrance region $(\mathrm{L} / \mathrm{D}=10)$ become a clear slug flow downstream and it occurs in a wider range of superficial gas velocity. The transition line to slug-annular and the 
transition to unstable annular flow are shifted to higher gas velocities in the downstream region. At the entrance of the capillary tube, the flow is disturbed, and the stable annular flow could not be visualized, while downstream far from the inlet zone the two-phase flow is established and is rather "laminar" and stable. Then, we may say that when the buoyancy force $\left(F_{A}=\rho_{L} g V_{G}\right)$ and liquid inertia force $\left(F_{L I}=1 / 2 \rho_{L} U_{L S}{ }^{2}\right)$ and dominant and low shear force $\left(F_{\mu G}=\mu_{\mathrm{L}}\left(\mathrm{U}_{\mathrm{GS}}-\mathrm{U}_{\mathrm{LS}}\right) \mathrm{S}_{\mathrm{LG}} / \mathrm{D}\right)$ at the interface, the bubbly flow takes place. When increasing the shear force at the interface (decreasing the liquid velocity), the slug flow is settled followed by unstable annular flow when the gas velocity is increased.

\subsubsection{Horizontal two-phase flow pattern}

The drawn two-phase flow maps resulting from the visualization at $\mathrm{L} / \mathrm{D}=10$ and downstream at $\mathrm{L} / \mathrm{D}=420$ are different (Fig. 12). In fact, for low superficial gas velocity the transition line bubbly-bubbly/slug slips to lower superficial gas velocity when going from $\mathrm{L} / \mathrm{D}=10$ to $\mathrm{L} / \mathrm{D}=420$. This is due to the effect of coalescence phenomenon along the tube. For moderate and high superficial gas velocity, the transition lines move to higher superficial gas velocities. This is due to breakup of the gas phase. These differences in the behavior might be attributed to inertia, buoyancy, shear stresses and interfacial forces that are quite different according to the position in the pipe. At the entrance of the pipe, at low gas velocity buoyancy forces are dominant giving rise to a bubbly flow pattern. When increasing the superficial gas velocity, the gas inertia as well as the liquid shear stress increase leading to slug and annular flow patterns respectively. Downstream, far from the inlet, a "laminar" two-phase flow is observed (see Zeguai et al., 2013). In this zone, the gas shear stresses are dominant giving rise to annular or plug/slug flow pattern.

\subsubsection{Downward two-phase flow pattern}

As illustrated in Fig. 13, the effect of liquid superficial velocity is more pronounced in the entrance region $(\mathrm{L} / \mathrm{D}=10)$; while it has much less effect in the downstream region 
particularly at high liquid superficial velocities. Several flow regimes are clearly identified: bubbly, bubbly/slug, slug, unstable annular, and annular. The two maps $(\mathrm{L} / \mathrm{D}=10$ and $\mathrm{L} / \mathrm{D}=420$ ) reveal that the same flow patterns exist. Nevertheless, they do not occur in the same velocity ranges. The demarcation lines have different behavior.

For very low liquid superficial velocity $\left(\mathrm{U}_{\mathrm{LS}}<0.005 \mathrm{~m} / \mathrm{s}\right)$ the flow pattern is annular at $\mathrm{L} / \mathrm{D}=$ 10 and remains annular downstream at $\mathrm{L} / \mathrm{D}=420$ independently of the gas inertia i.e. the value of the gas superficial velocity. In this configuration, the action of buoyancy is in opposite direction to the two-phase flow. At higher superficial liquid velocity, above 0.05 $\mathrm{m} / \mathrm{s}$, the bubbly flow in the inlet zone persists for a wider range of gas velocity than it does downstream at $\mathrm{L} / \mathrm{D}=420$. The bubbly pattern at $\mathrm{L} / \mathrm{D}=10$ evolves to either a bubbly/slug transition or a slug flow away from the entrance region. Like the upward and horizontal twophase flow, the flow maps for downward flow exhibit the same trend. For low superficial gas the transition line from bubbly to bubbly/slug slips to lower gas velocities at $L / D=420$. This might be due to coalescence of the bubbles along the tube, this coalescence is enhanced in this configuration by the gravity effects (buoyancy). While the unstable annular structure at $\mathrm{L} / \mathrm{D}=$ 10 becomes rather a slug-annular flow at $\mathrm{L} / \mathrm{D}=420$ and the transition to the annular flow pattern is shifted to higher gas velocities at the downstream location. In this case the breakup of the gas phase occurs.

According to the visualizations and the drawn flow maps, we may say that the two-phase flow is not established in the entrance region $(\mathrm{L} / \mathrm{D}=10)$ and the flow pattern is rather stable at the downstream location. From these results it is difficult to ensure that the two-phase is established for all the configurations observed. Nevertheless, some two-phase flow patterns remain unchanged between $\mathrm{L} / \mathrm{D}=10$ and $\mathrm{L} / \mathrm{D}=420$. In this later case, we may assume that the two-phase flow is established.

\subsection{Discussion}


In this two-phase flow system, the physical parameters: gravity (tube orientation), gas inertia, liquid shear stress play a role in the two-phase flow pattern and the transition lines. In what follows let's determine the importance of these effects from the experimental results obtained in this study.

We focus the discussion of the maps for the three orientations (vertical upward VU, horizontal $\mathrm{H}$ and vertical downward VD) at the location $\mathrm{L} / \mathrm{D}=420$ where the two-phase flow is "laminar" with a smooth interface. We examine the topological structure of the two-phase flow according to the superficial velocity of the gas and liquid phases and we attempt to describe the role of the main forces on these structures.

Let's consider the case of vertical upward flow as a reference case and the two-phase flow map at the location $\mathrm{L} / \mathrm{D}=420$ is used for comparison purposes. Figure 14 plots this map in terms of superficial liquid velocity versus superficial gas velocity. Basically, we observe the three main structures, namely bubbly, slug and annular, although the annular flow is unstable. With this upward flow, the gravity affects both phases differently. Gravity manifests itself through the buoyancy force that acts on the dispersed phase (bubbles and slugs) and it helps them to detach from the nozzle and contrarily, it acts on the liquid phase through its density. The buoyancy force is oriented upward while the weight of the gas and liquid phases are oriented downward. Therefore, the buoyancy aids the gas phase in its ascending motion and bubble formation. For instance, the gravity effect cooperates with the shear force through the weight of the liquid phase, whereas the buoyancy force is opposed to the shear force and the weight of liquid and gas (for the gas phases the weight is negligible). When increasing the superficial gas velocity while keeping the superficial liquid velocity constant, the interfacial shear force and gas inertia forces augmented and the flow pattern changes successively from a bubbly to slug and to unstable annular structure. We may say that the increase of the shear force as well as the gas inertia helps to evolve successively from a bubbly, slug to unstable annular flow pattern. 
For very low superficial gas velocity, at high superficial liquid velocity the liquid inertia effects as well as the shear liquid flow induce a bubbly regime. When decreasing the superficial liquid velocity (decreasing liquid inertia), the gas bubble size increase and give rise to slug flow. At very low liquid velocity the annular flow takes place.

For the case of a downward two-phase flow (Fig. 14), the weight of the liquid and the gas phases are in the same direction of the two-phase flow while the buoyancy force for the gas phase is oriented upward. In this case, the buoyancy cooperates with the liquid shear force, hence it reduces the formation of bubbles and slugs (dispersed phase). By increasing the superficial gas velocity while keeping the superficial liquid velocity constant, the annular flow is easily obtained. The gravity effect through the liquid phase helps the annular flow to be stable. The transition lines from one flow pattern to another are shifted to smaller superficial gas velocities compared to the upward flow case (Fig. 14).

For the horizontal orientation (Fig. 14), we still observe the three main structures (bubbly, slug, annular). However, the gravity effect is perpendicular to the two-phase flow direction. The gravity acts in the transverse direction creating a non-symmetrical two-phase flow pattern in the cross-section of the tube. The buoyancy force is upward and pushes the gas phase to the top of the cross-section, while the liquid phase is moved to the bottom of the cross-section. Therefore, bubbles and slugs are in the upper zone of the cross section and the liquid film around the slugs or the annular pattern is not symmetrical. The gravity aids the formation of the dispersed phase (bubbles and slugs) and then the map is closer to the map of the upward flow. In this case, the transition lines for this orientation are in between the transition lines of upward and downward two-phase flow as shown on Fig.14.

The evolution of the flow patterns along the tube are described by the comparison of the maps at the two locations, in the entrance of mixing zone at $\mathrm{L} / \mathrm{D}=10$ and far downstream at $\mathrm{L} / \mathrm{D}=$ 420. The evolution is characterized by the augmentation or diminution of the size of the gas entities. Two phenomena may cause the change in flow patterns: i) coalescence of bubbles or 
slugs to yield slugs or annular patterns respectively or ii) breakup of annular or slug patterns to yield slugs or bubbles respectively.

The comparison of the maps at $\mathrm{L} / \mathrm{D}=10$ and $\mathrm{L} / \mathrm{D}=420$, for the vertical upward (Fig. 11) and horizontal orientation (Fig. 12), show that the transition lines slips similarly to the high superficial gas velocity. This means that a slug, slug/annular and unstable annular or annular at $L / D=10$ become slug at $L / D=420$. This is basically due to the breakup phenomenon probably induced by a capillary instability. By increasing the superficial gas velocity, the unstable annular or annular pattern evolves successively to slug/annular and annular at $\mathrm{L} / \mathrm{D}=420$ (see Figs. 11 and 12).

The coalescence occurs more frequently with bubbles as it can be observed with the transition lines that are shifted to the smaller superficial gas velocity where the bubbles are of bigger size at $\mathrm{L} / \mathrm{D}=420$ compared to those developed at $\mathrm{L} / \mathrm{D}=10$. However, for the case of a downward two-phase flow, the transition lines slips weakly to the high superficial gas velocity (Fig. 13), where the trend of the transition lines of one pattern to another is different between the two explored regions, the entrance zone at $\mathrm{L} / \mathrm{D}=10$ and far downstream at $\mathrm{L} / \mathrm{D}=420$.

\section{Conclusion}

An experimental device is designed and built to study the evolution of gas-liquid two-phase flow patterns in a long capillary tube. The experiments are carried out in a way that inlet flow rates are carefully controlled and chosen in ranges that allow smooth interfaces. Flow visualizations are recorded with a high speed camera at two locations: in the entrance region where the two phases are brought in contact $(L / D=10)$ and far downstream at $L / D=420$. Results are obtained for two configurations: upward and downward flow for a vertical tube orientation. These results complete those obtained for a horizontal orientation in a previous paper. For both configurations, visualized flow patterns are similar to those reported in the 
literature (bubbly, slug and annular). However, it should be pointed out that unlike previous studies, we observed these flow structures in very different ranges of velocity compared to those commonly considered in the literature. In fact, we highlighted those flow patterns at very low superficial velocities.

Comparison between the flow patterns, at the two locations highlight the evolution along the tube. Under certain conditions, the flow pattern remains unchanged, but under other operating conditions the flow pattern evolves to another flow structure probably due to either coalescence or breakup phenomena.

Then, two-phase flow maps are drawn and compared to the horizontal tube in order to highlight the effect of gravity without neglecting other parameters. Indeed, the horizontal and vertical upward flows are much alike and present similar transition boundaries. However, the vertical downward flow exhibits a quite different behavior and the transitions occur at very different values of velocities.

\section{References}

Amador, C., Salman, W., Sanguanpiyapan, S., Gavriilidis, A., Angeli, P., 2004. Effect of gasinlet conditions on the mechanism of Taylor flow formation. In: Fifth Inetrnational Conference on Multiphase Flow, ICMF’04 Yokohama, Japan, Paper No. 515.

Barnea, D., Luninski, Y., Taitel, Y., 1983. Flow pattern in horizontal and vertical two phase flow in small diameter pipes. Can. J. Chem. Eng 61, 617-620.

Bhagwat, Swanand M., Ghajar, Afshin J., 2012. Similarities and differences in the flow patterns and void fraction in vertical upward and downward two-phase flow. Exp. Therm. and Fluid Sci. 39, 213-227.

Biswas, J., Greenfield, P. F., 1985. Two-phase flow through vertical capillaries - existence of a stratified flow pattern. Int. J. of Multiphase Flow, 11, 553-563. 
Brauner, N., Barnea, D., 1986. Slug/Churn transition in upward gas-liquid flow. Chem. Eng. Sci, Vol 41, N0. 1, 159-163.

Chen. W., Twu. M., Pan, C., 2002. Gas-liquid two-phase flow in micro-channels. Int. J. of Multiphase Flow, 28, 1235-1247.

Chinnov, E. A., Kabov, O. A., 2006. Two-phase flows in pipes and capillary channels. High temperature. Vol. 44, No. 5, pp. 773-791.

Fukano, T., Kariyasaki, A., Kagawa, M., 1990. Flow patterns and pressure drop in isothermal gas-liquid concurrent flow in a horizontal capillary tube. Trans. JSME (Set. B) 56, 23182326, in Japanese.

Fukano, T., Kariyasaki, A., 1993. Characteristics of gas-liquid two-phase flow in a capillary tube. Nucl. Eng. Des. 141, 59-68.

Galbiati, L., Andreini, P., 1992. Flow pattern transition for vertical Downward two-phase flow in capillary tubes. Inlet mixing effects. Int. Comm. Heat Mass Transfer, 19, 791-799.

Hassan, I., Vaillancourt, M., Pehlivan, K., 2005. Two-phase flow regime transitions in microchannels : a comparative experimental study. Microscale Thermophys. Eng. 9, 165182.

Hijikata, K., Mori, Y., Nagasaki, T., Nohata, K., 1985. A study on high speed two-phase flow through a capillary tube. Trans. JSME (Ser. B) 51, 1033-1041, in Japanese.

Ide, H., Kariyasaki, A., Fukano, T., 2007, Fundamental data on the gas-liquid two-phase flow in minichannels. Int. J. of Therm Sci. 46, 519-530. 
Kariyasaki, A., Fukano, T., Ousaka, A., Kagawa, M., 1991. Characteristics of time-varying void fraction in isothermal air-water cocurrent flow in a horizontal capillary tube. Trans. JSME (Ser. B) 57, 4036-4043, in Japanese.

Kariyasaki, A., Fukano, T., Ousaka, A., Kagawa, M., 1992. Isothermal air-water two-phase up and downward flows in a vertical capillary tube (lst report, Flow pattern and void fraction). Trans. JSME (Ser. B) 58, 2684-2690, in Japanese.

Milan, M., Borhani, N., Thome, J. R., 2013. Adiabatic vertical downward air-water flow pattern map: Influence of inlet device, flow development length and hysteresis effects. Int. J. of Multiphase Flow, 56, 126-137.

Mishima, K., Hibiki, T., 1996. Some characteristics of air-water two-phase flow in small diameter vertical tubes. Int. J. of Multiphase Flow, Vol 22, No. 4, 703-712.

Saisorn, S., Wongwises, S., 2008. Review of two-phase flow gas-liquid adiabatic flow characteristics in micro-channels. Renewable and Sustainable Energy Reviews 12, 824 838.

Serizawa, A., Feng. Z., Kawara, Z., 2002. Two-phase flow in microchannels. Exp. therm and fluid sci. 26, 703-714.

Shao, N., Gavriilidis, A., Angeli, P., 2008. Effect of inlet conditions on gas-liquid flow regimes in microchannels. In: First International Conference on Microfluidics, 10-12 December, Bologna, Italy.

Shao, N., Gavriilidis, A., Angeli, P., 2009. Flow regimes for adiabatic gas-liquid flow in microchannels. Chem. Eng. Sci. 64, 2749-2761. 
Sugawara, S., Katsuta, K., 1shihara, I., Muto, T., 1967. Consideration on the pressure loss of two-phase flow in small-diameter tubes. In Proc. 4th National Heat Transfer Symp. of Japan, 169-172, in Japanese.

Wölk, G., Dreyer, M., Rath, H.J., 2000. Flow patterns in small diameter vertical non-circular Channels. Int. J. of Multiphase Flow, 26, 1037-1061.

Zeguai, S., Chikh S., Tadrist L., 2013. Experimental study of two-phase flow pattern evolution in a horizontal circular tube of small diameter in laminar flow conditions. Int. J. of Multiphase Flow, 55, 99-110.

Zhao, T.S., Bi, Q.C., 2001. Co-current air-water two-phase flow patterns in vertical triangular microchannels. Int. J. of Multiphase Flow, 27, 765-782. 


\section{Figure captions}

Fig.1: Two-phase flow maps for air-water upward flow in vertical tubes of small diameter $(2 \mathrm{~mm}<\mathrm{D}<6 \mathrm{~mm})$ : published results in the literature by the several authors mentioned on the map.

Fig.2: Two-phase flow maps for air-water downward flow in vertical tubes of small diameter $(3 \mathrm{~mm}<\mathrm{D}<8 \mathrm{~mm})$ : published results in the literature by the several authors mentioned on the map.

Fig.3: Sketch of the experimental setup with the several components and the data acquisition system.

Fig.4: Air/water injection system.

Fig.5: Typical patterns observed at (a) $\mathrm{L} / \mathrm{D}=10$ and (b) $\mathrm{L} / \mathrm{D}=420$ for upward flow and low liquid superficial velocity, $\mathrm{U}_{\mathrm{LS}}=0.78 \times 10^{-3} \mathrm{~m} / \mathrm{s}$.

Fig.6: Typical patterns observed at (a) $\mathrm{L} / \mathrm{D}=10$ and (b) $\mathrm{L} / \mathrm{D}=420$ for upward flow and moderate liquid superficial velocity, $\mathrm{U}_{\mathrm{LS}}=29 \times 10^{-3} \mathrm{~m} / \mathrm{s}$.

Fig.7: Typical patterns observed at (a) $L / D=10$ and (b) $L / D=420$ for upward flow and high liquid superficial velocity, $\mathrm{U}_{\mathrm{LS}}=59 \times 10^{-3} \mathrm{~m} / \mathrm{s}$.

Fig.8: Typical patterns observed at (a) $\mathrm{L} / \mathrm{D}=10$ and (b) $\mathrm{L} / \mathrm{D}=420$ for downward flow and low liquid superficial velocity, $\mathrm{U}_{\mathrm{LS}}=0.78 \times 10^{-3} \mathrm{~m} / \mathrm{s}$.

Fig.9: Typical patterns observed at (a) $\mathrm{L} / \mathrm{D}=10$ and (b) $\mathrm{L} / \mathrm{D}=420$ for downward flow and moderate liquid superficial velocity, $\mathrm{U}_{\mathrm{LS}}=29 \times 10^{-3} \mathrm{~m} / \mathrm{s}$.

Fig. 10: Typical patterns observed at (a) $L / D=10$ and (b) $L / D=420$ for downward flow and high liquid superficial velocity, $\mathrm{U}_{\mathrm{LS}}=59 \times 10^{-3} \mathrm{~m} / \mathrm{s}$.

Fig.11: Two-phase flow map of air water in a tube of $3 \mathrm{~mm}$ diameter for vertical upward orientation with respect to gravity, at $\mathrm{L} / \mathrm{D}=10$ and at $\mathrm{L} / \mathrm{D}=420$. 
Fig.12: Two-phase flow map of air water in a tube of $3 \mathrm{~mm}$ diameter for horizontal orientation with respect to gravity, at $\mathrm{L} / \mathrm{D}=10$ and at $\mathrm{L} / \mathrm{D}=420$.

Fig.13: Two-phase flow map of air water in a tube of $3 \mathrm{~mm}$ diameter for vertical downward orientation with respect to gravity, at $\mathrm{L} / \mathrm{D}=10$ and at $\mathrm{L} / \mathrm{D}=420$.

Fig.14: Two-phase flow map of air water in a tube of $3 \mathrm{~mm}$ diameter: comparison between two-phase flow map for vertical upward, horizontal, and vertical downward orientations with respect to gravity, at $\mathrm{L} / \mathrm{D}=10$ and at $\mathrm{L} / \mathrm{D}=420$. 


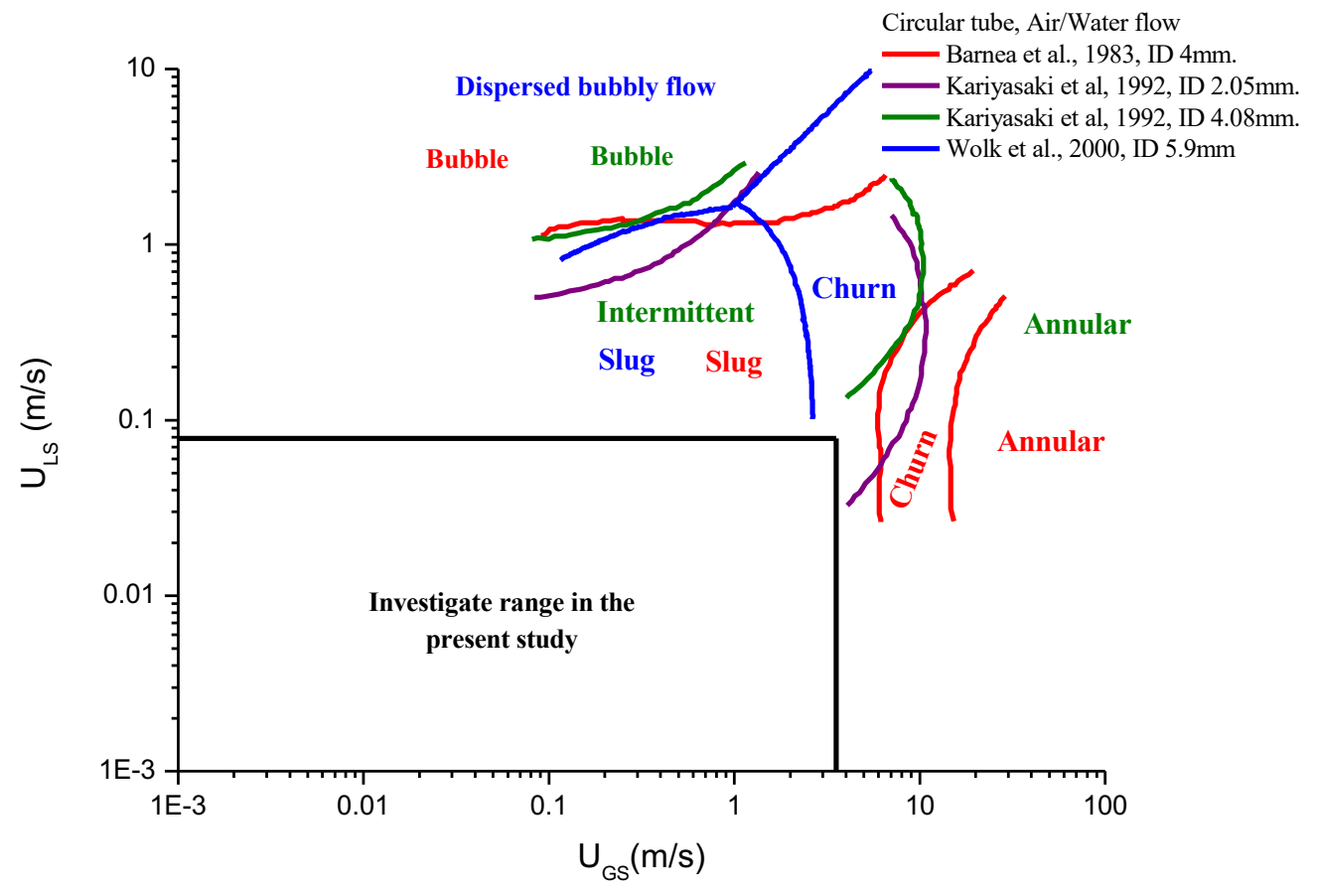

Fig.1: Two-phase flow maps for air-water upward flow in vertical tubes of small diameter $(2 \mathrm{~mm}<\mathrm{D}<6 \mathrm{~mm})$ : published results in the literature by the several authors mentioned on the map. 


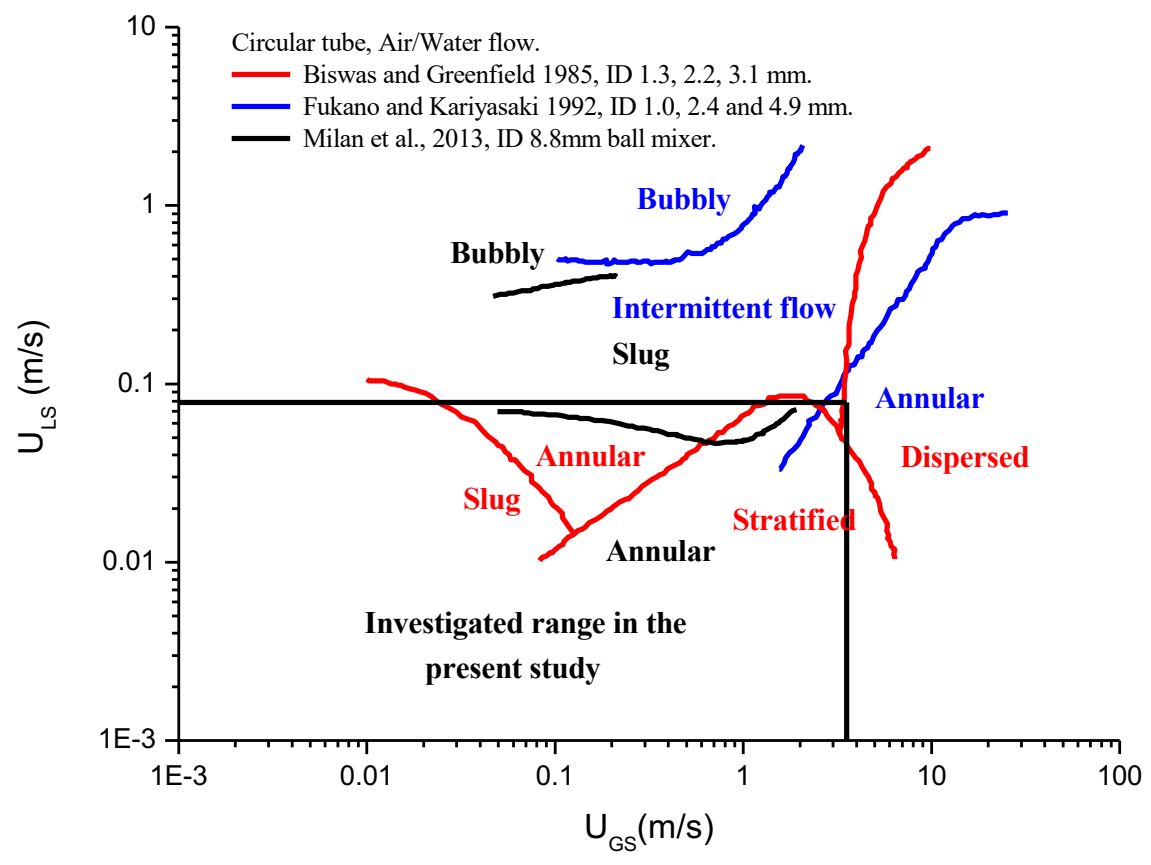

Fig.2: Two-phase flow maps for air-water downward flow in vertical tubes of small diameter $(3 \mathrm{~mm}<\mathrm{D}<8 \mathrm{~mm})$ : published results in the literature by the several authors mentioned on the map. 


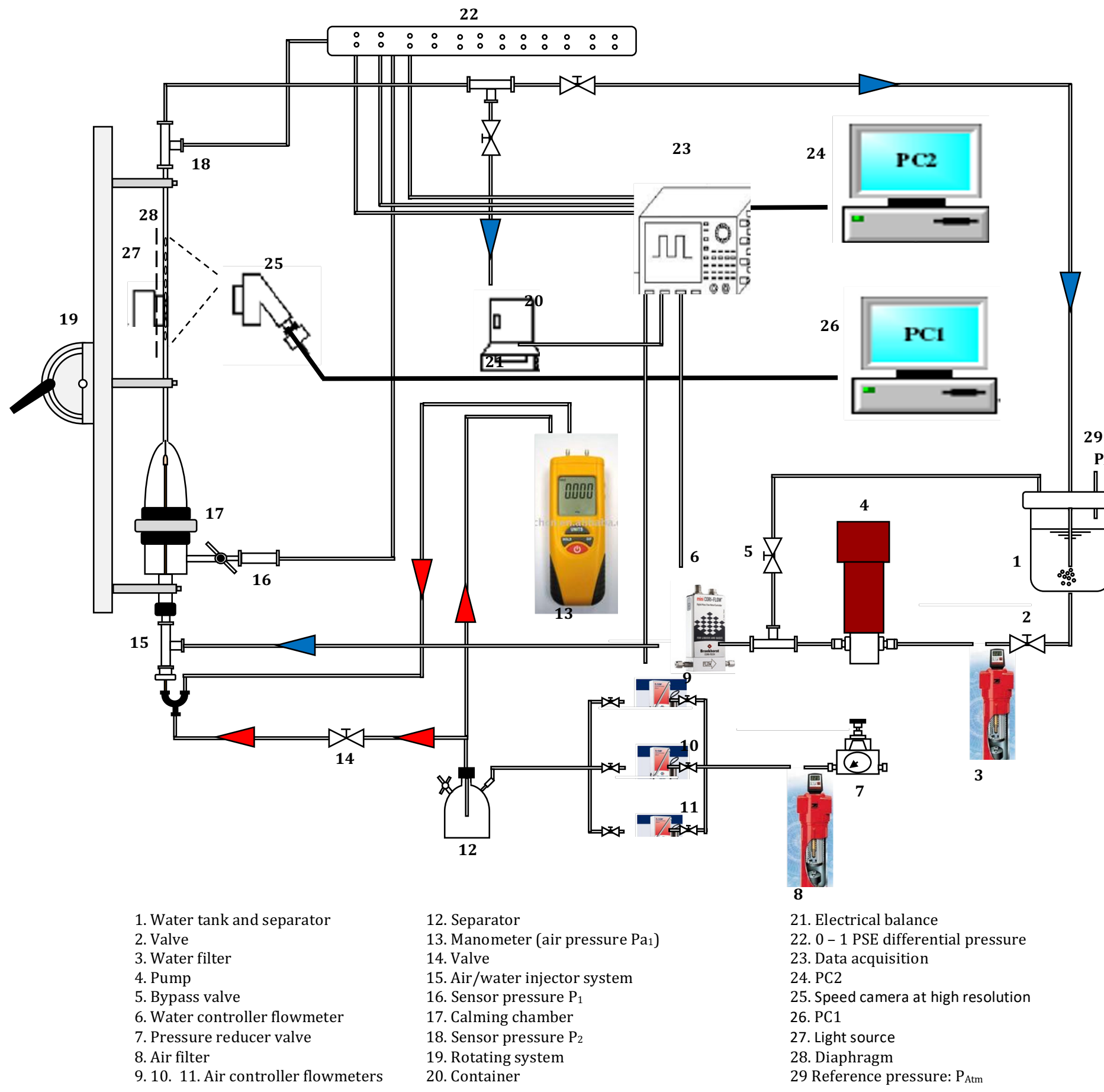

Fig.3: Sketch of the experimental setup with the several components and the data acquisition system. 


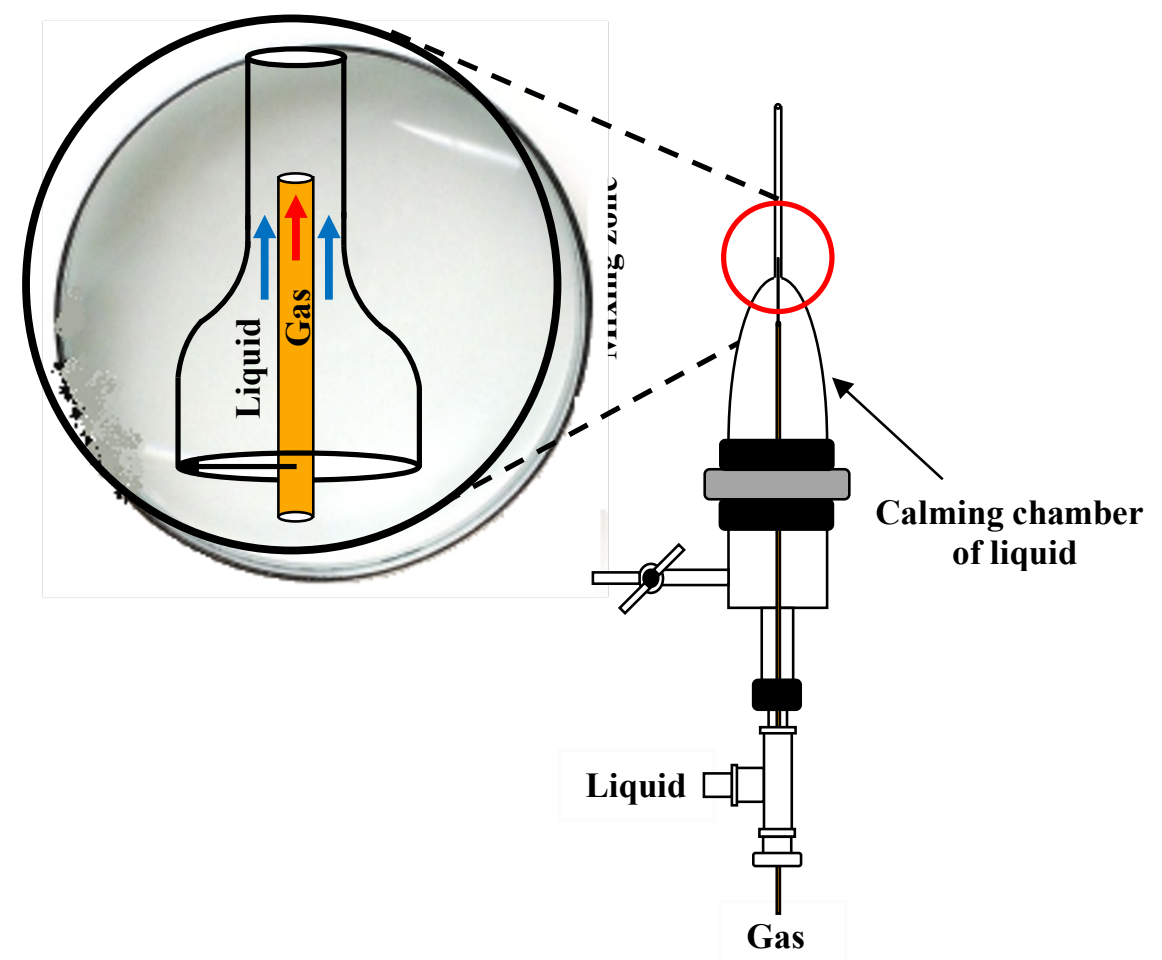

Fig.4: Air/water injection system. 


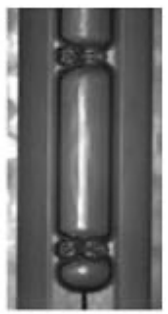

(a.1) Bubbly / Slug $\mathrm{U}_{\mathrm{GS}}=3.8 \times 10^{-3} \mathrm{~m} / \mathrm{s}$

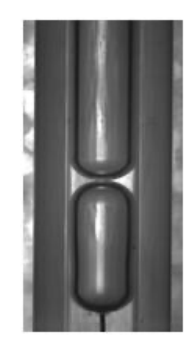

(a.2) Slug $\mathrm{U}_{\mathrm{GS}}=8 \times 10^{-3} \mathrm{~m} / \mathrm{s}$

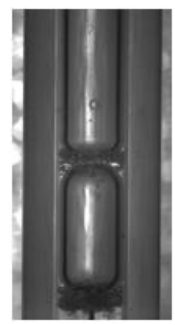

(a.3) Slug $\mathrm{U}_{\mathrm{GS}}=47 \times 10^{-3} \mathrm{~m} / \mathrm{s}$

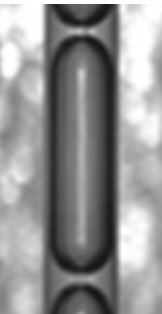

(b.1) Slug $\mathrm{U}_{\mathrm{GS}}=3.8 \times 10^{-3} \mathrm{~m} / \mathrm{s}$

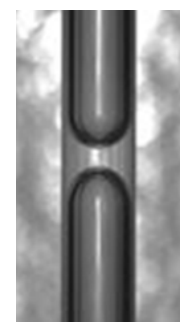

(b.2) Slug $\mathrm{U}_{\mathrm{GS}}=8 \times 10^{-3} \mathrm{~m} / \mathrm{s}$

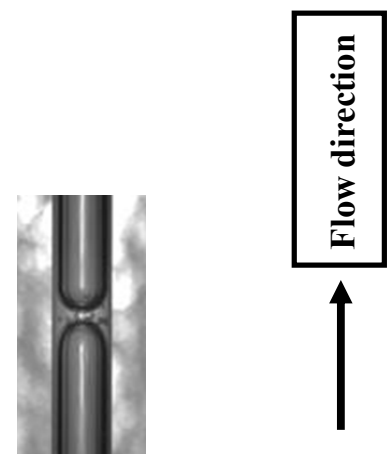

(b.3) Slug $\mathrm{U}_{\mathrm{GS}}=47 \times 10^{-3} \mathrm{~m} / \mathrm{s}$

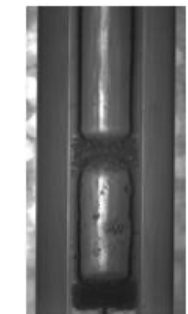

(a.4) Slug $\mathrm{U}_{\mathrm{GS}}=146 \times 10^{-3} \mathrm{~m} / \mathrm{s}$
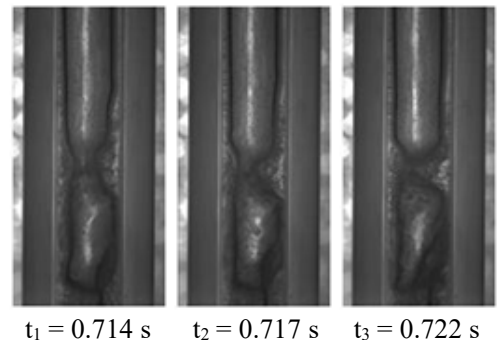

(a.5) Unstable annular $\mathrm{U}_{\mathrm{GS}}=377 \times 10^{-3} \mathrm{~m} / \mathrm{s}$

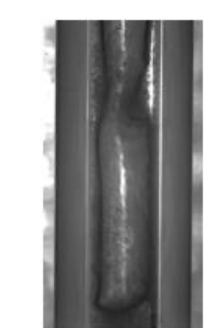

(a.6) Unstable annular $\mathrm{U}_{\mathrm{GS}}=778 \times 10^{-3} \mathrm{~m} / \mathrm{s}$

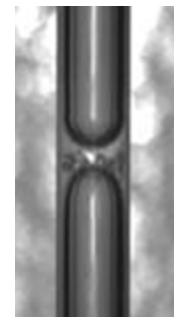

(b.4) Slug $\mathrm{U}_{\mathrm{GS}}=146 \times 10^{-3} \mathrm{~m} / \mathrm{s}$

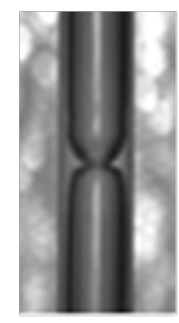

(b.5) Slug / annular $\mathrm{U}_{\mathrm{GS}}=377 \times 10^{-3} \mathrm{~m} / \mathrm{s}$

1- downward motion before breakup (Reversal flow)

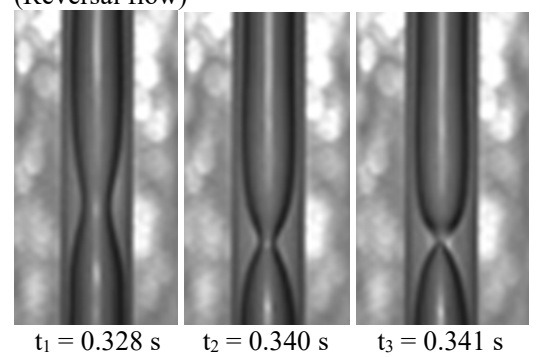

2- upward motion after breakup (Co-current flow)

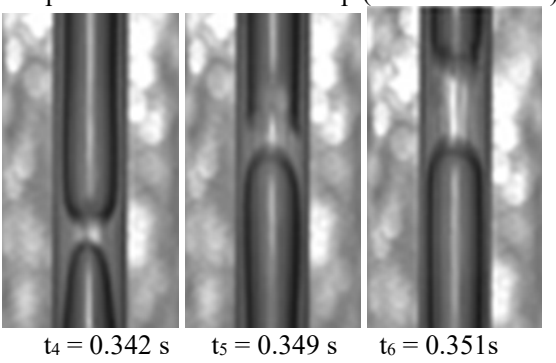

(b.6) Slug / Unstable annular $\mathrm{U}_{\mathrm{GS}}=778 \times 10^{-3} \mathrm{~m} / \mathrm{s}$

Fig.5: Typical patterns observed at (a) $\mathrm{L} / \mathrm{D}=10$ and (b) $\mathrm{L} / \mathrm{D}=420$ for upward flow and small liquid superficial velocity, $U_{L S}=0.78 \times 10^{-3} \mathrm{~m} / \mathrm{s}$. 


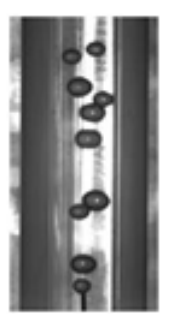

(a.1) Dispersed Bubbly $\mathrm{U}_{\mathrm{GS}}=3.8 \times 10^{-3} \mathrm{~m} / \mathrm{s}$

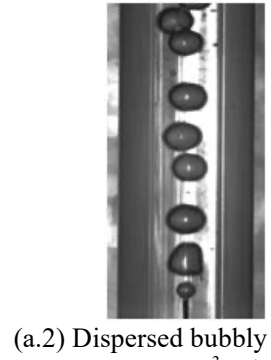

$\mathrm{U}_{\mathrm{GS}}=24 \times 10^{-3} \mathrm{~m} / \mathrm{s}$

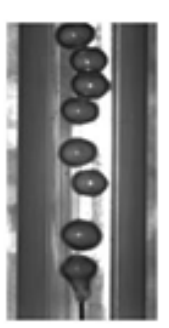

(a.3) Dispersed bubbly $\mathrm{U}_{\mathrm{GS}}=28 \times 10^{-3} \mathrm{~m} / \mathrm{s}$

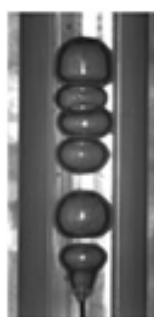

(a.4) Bubbly/Slug $\mathrm{U}_{\mathrm{GS}}=30 \times 10^{-3} \mathrm{~m} / \mathrm{s}$

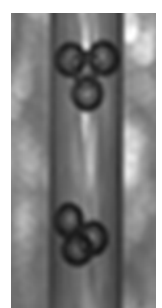

(b.1) Dispersed bubbly $\mathrm{U}_{\mathrm{GS}}=3.8 \times 10^{-3} \mathrm{~m} / \mathrm{s}$
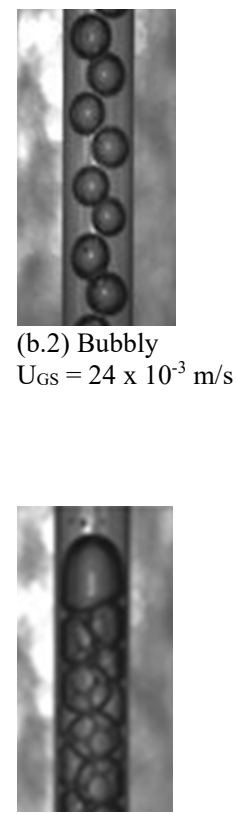

(b.3) Bubbly/Slug $\mathrm{U}_{\mathrm{GS}}=28 \times 10^{-3} \mathrm{~m} / \mathrm{s}$

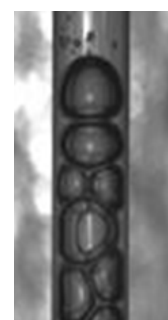

(b.4) Bubbly/Slug $\mathrm{U}_{\mathrm{GS}}=30 \times 10^{-3} \mathrm{~m} / \mathrm{s}$

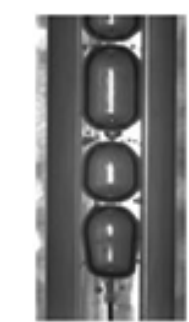

(a.5) Slug $\mathrm{U}_{\mathrm{GS}}=60 \times 10^{-3} \mathrm{~m} / \mathrm{s}$

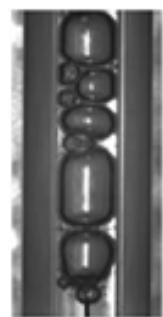

(a.6) Disordered bubbly/slug $\mathrm{U}_{\mathrm{GS}}=106 \times 10^{-3} \mathrm{~m} / \mathrm{s}$

(b.6) Slug $\mathrm{U}_{\mathrm{GS}}=106 \times 10^{-3} \mathrm{~m} / \mathrm{s}$
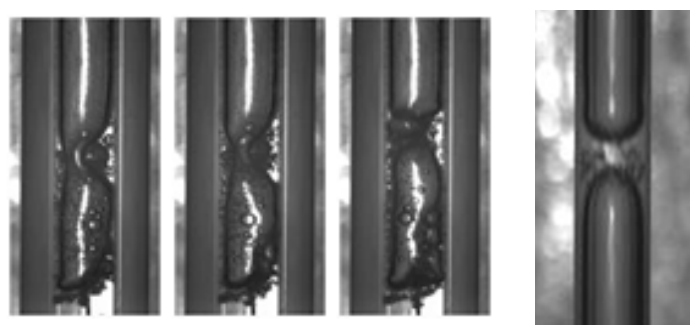

$\mathrm{t}_{1}=0.661 \mathrm{~s} \quad \mathrm{t}_{2}=0.665 \mathrm{~s} \quad \mathrm{t}_{3}=0.670 \mathrm{~s}$

(a.7) Unstable annular

(b.7) Slug

$\mathrm{U}_{\mathrm{GS}}=212 \times 10^{-3} \mathrm{~m} / \mathrm{s}$

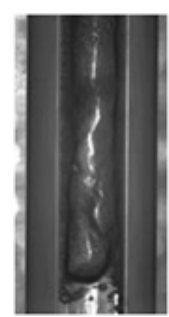

(a.8) Unstable annular $\mathrm{U}_{\mathrm{GS}}=778 \times 10^{-3} \mathrm{~m} / \mathrm{s}$

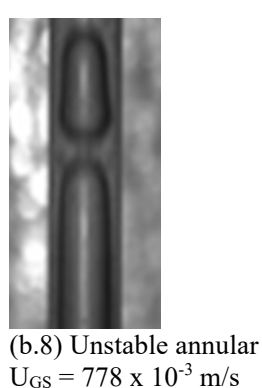

Fig.6: Typical patterns observed at (a) $L / D=10$ and (b) $L / D=420$

for upward flow and moderate liquid superficial velocity $U_{L S}=29 \times 10^{-3} \mathrm{~m} / \mathrm{s}$. 


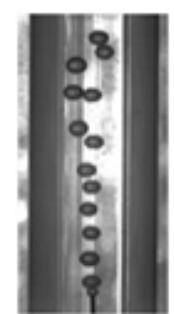

(a.1) Dispersed Bubbly $\mathrm{U}_{\mathrm{GS}}=3.8 \times 10^{-3} \mathrm{~m} / \mathrm{s}$

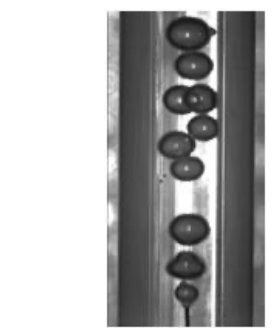

(a.2) Dispersed bubbly $\mathrm{U}_{\mathrm{GS}}=32 \times 10^{-3} \mathrm{~m} / \mathrm{s}$

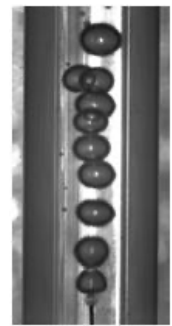

(a.3) Dispersed bubbly $\mathrm{U}_{\mathrm{GS}}=33 \times 10^{-3} \mathrm{~m} / \mathrm{s}$

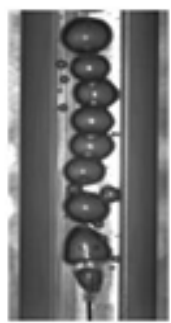

(a.4) Bubbly $\mathrm{U}_{\mathrm{GS}}=57 \times 10^{-3} \mathrm{~m} / \mathrm{s}$

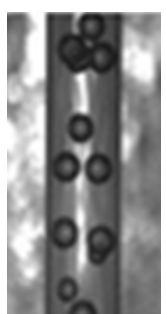

(b.1) Dispersed bubbly $\mathrm{U}_{\mathrm{GS}}=3.8 \times 10^{-3} \mathrm{~m} / \mathrm{s}$

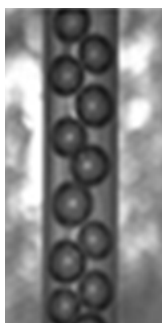

(b.2) Dispersed bubbly $\mathrm{U}_{\mathrm{GS}}=32 \times 10^{-3} \mathrm{~m} / \mathrm{s}$

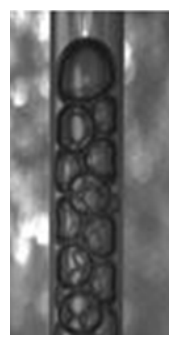

(b.3) Bubbly/Slug $\mathrm{U}_{\mathrm{GS}}=33 \times 10^{-3} \mathrm{~m} / \mathrm{s}$

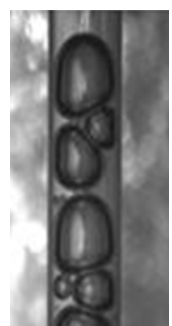

(b.4) Bubbly/Slug $\mathrm{UGS}=57 \times 10^{-3} \mathrm{~m} / \mathrm{s}$

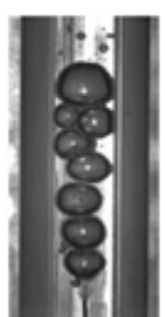

(a.5) Bubbly/Slug $\mathrm{U}_{\mathrm{GS}}=61 \times 10^{-3} \mathrm{~m} / \mathrm{s}$

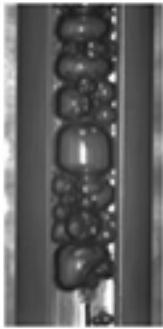

(a.6) Disordered Bubbly/Slug $\mathrm{U}_{\mathrm{GS}}=165 \times 10-3 \mathrm{~m} / \mathrm{s}$

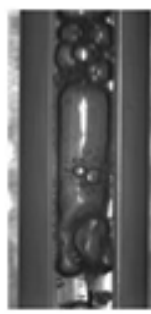

$\mathrm{t}_{1}=0.073 \mathrm{~s}$
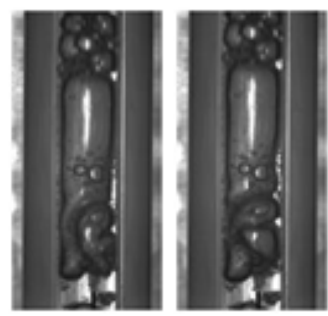

$\mathrm{t}_{2}=0.075 \mathrm{~s} \quad \mathrm{t}_{3}=0.077 \mathrm{~s}$

(a.7) Unstable annular $\mathrm{U}_{\mathrm{GS}}=212 \times 10^{-3} \mathrm{~m} / \mathrm{s}$

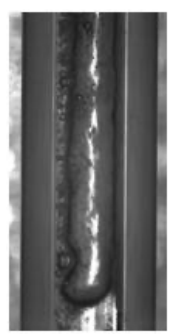

(a.8) Unstable annular $\mathrm{U}_{\mathrm{GS}}=778 \times 10^{-3} \mathrm{~m} / \mathrm{s}$ (b.6) Slug $\mathrm{U}_{\mathrm{GS}}=165 \times 10^{-3} \mathrm{~m} / \mathrm{s}$ $\mathrm{U}_{\mathrm{GS}}=212 \times 10^{-3} \mathrm{~m} / \mathrm{s}$
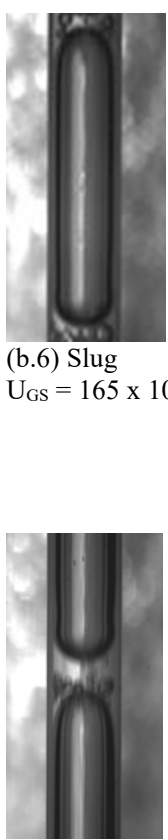

\section{(b.7) Slug} U.

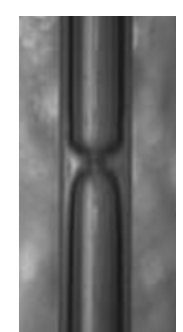

(b.8) Slug/annular $\mathrm{U}_{\mathrm{GS}}=778 \times 10^{-3} \mathrm{~m} / \mathrm{s}$

Fig.7: Typical patterns observed at (a) $\mathrm{L} / \mathrm{D}=10$ and (b) $\mathrm{L} / \mathrm{D}=420$ for upward flow and high liquid superficial velocity $U_{\mathrm{LS}}=59 \times 10^{-3} \mathrm{~m} / \mathrm{s}$. 

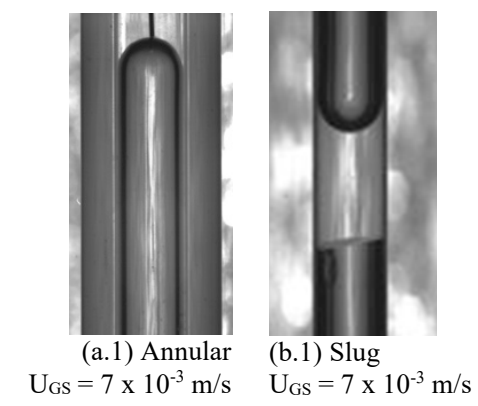

(a.2) Annular $\mathrm{U}_{\mathrm{GS}}=19 \times 10^{-3} \mathrm{~m} / \mathrm{s}$

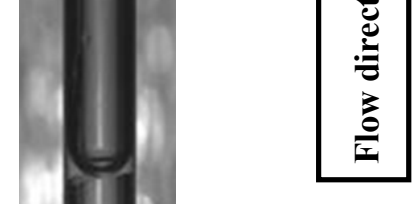

(b.2) Slug/annular $\mathrm{U}_{\mathrm{GS}}=19 \times 10^{-3} \mathrm{~m} / \mathrm{s}$
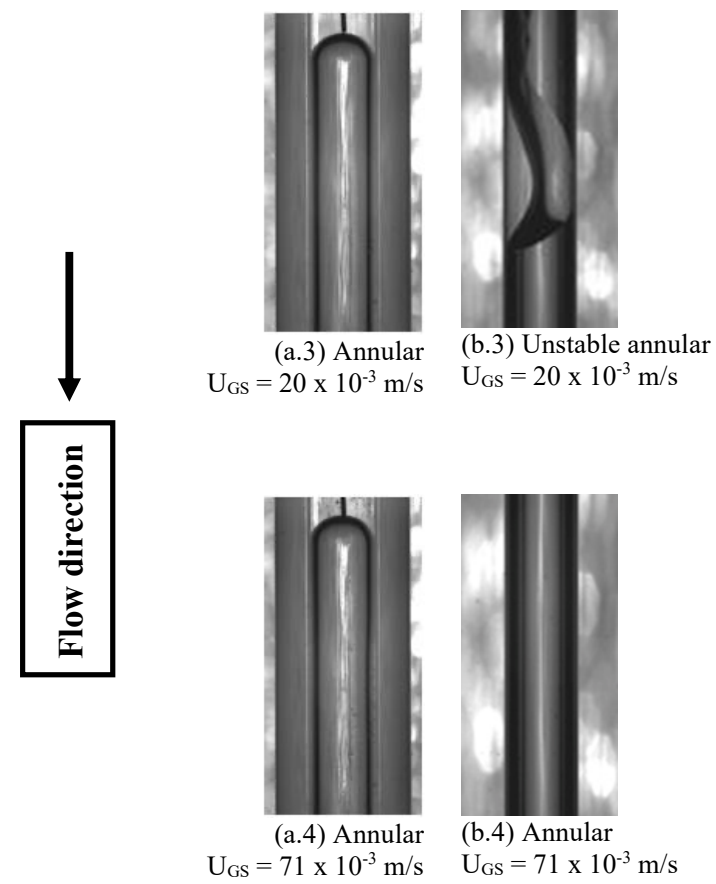

Fig.8: Typical patterns observed at (a) $\mathrm{L} / \mathrm{D}=10$ and (b) $\mathrm{L} / \mathrm{D}=420$ for downward flow and small liquid superficial velocity, $U_{\mathrm{LS}}=0.78 \times 10^{-3} \mathrm{~m} / \mathrm{s}$. 


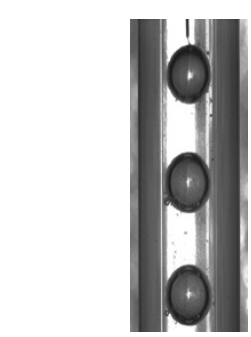

(a.1) Bubbly $\mathrm{U}_{\mathrm{GS}}=3.8 \times 10^{-3} \mathrm{~m} / \mathrm{s}$

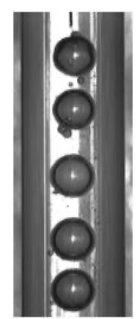

(a.2) Bubbly $\mathrm{U}_{\mathrm{GS}}=9 \times 10^{-3} \mathrm{~m} / \mathrm{s}$

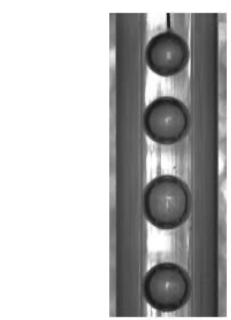

(a.3) Bubbly $\mathrm{U}_{\mathrm{GS}}=12 \times 10^{-3} \mathrm{~m} / \mathrm{s}$

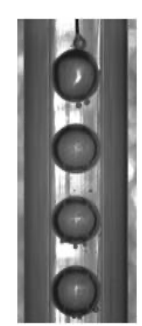

(a.4) Bubbly $\mathrm{U}_{\mathrm{GS}}=17 \times 10^{-3} \mathrm{~m} / \mathrm{s}$

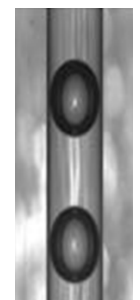

(b.3) Bubbly $\mathrm{U}_{\mathrm{GS}}=12 \times 10^{-3} \mathrm{~m} / \mathrm{s}$

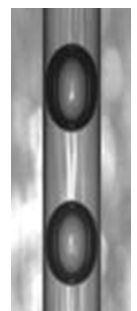

(b.4) Slug

$\mathrm{U}_{\mathrm{GS}}=17 \times 10^{-3} \mathrm{~m} / \mathrm{s}$

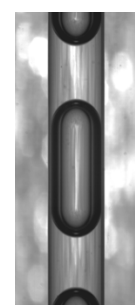

(b.5) Slug

$\mathrm{U}_{\mathrm{GS}}=43 \times 10^{-3} \mathrm{~m} / \mathrm{s}$
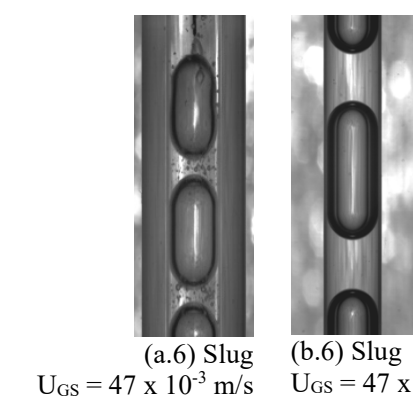

(b.6) Slug $\mathrm{U}_{\mathrm{GS}}=47 \times 10^{-3} \mathrm{~m} / \mathrm{s}$

(a.7) Breakup slug/annular $\mathrm{U}_{\mathrm{GS}}=76 \times 10^{-3} \mathrm{~m} / \mathrm{s}$
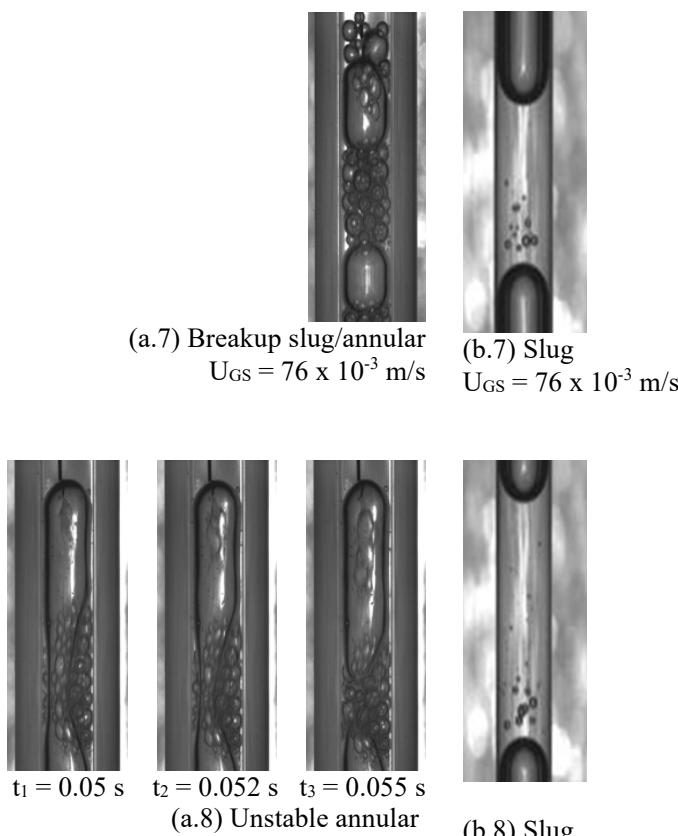

(a.8) Unstable annular
$\mathrm{U}_{\mathrm{GS}}=94 \times 10^{-3} \mathrm{~m} / \mathrm{s}$

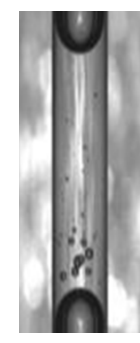

(b.8) Slug

$\mathrm{U}_{\mathrm{GS}}=94 \times 10^{-3} \mathrm{~m} / \mathrm{s}$

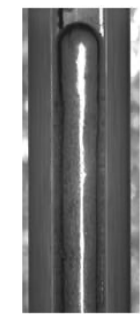

(a.9) Annular $\mathrm{U}_{\mathrm{GS}}=184 \times 10^{-3} \mathrm{~m} / \mathrm{s}$

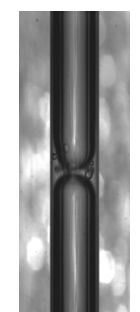

(b.9) Slug/annular $\mathrm{U}_{\mathrm{GS}}=184 \times 10^{-3} \mathrm{~m} / \mathrm{s}$
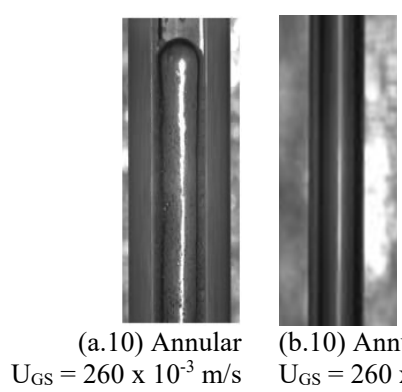

(b.10) Annular $\mathrm{U}_{\mathrm{GS}}=260 \times 10^{-3} \mathrm{~m} / \mathrm{s}$

Fig.9: Typical patterns observed at (a) $L / D=10$ and (b) $L / D=420$

for downward flow and moderate liquid superficial velocity, $U_{L S}=29 \times 10^{-3} \mathrm{~m} / \mathrm{s}$. 

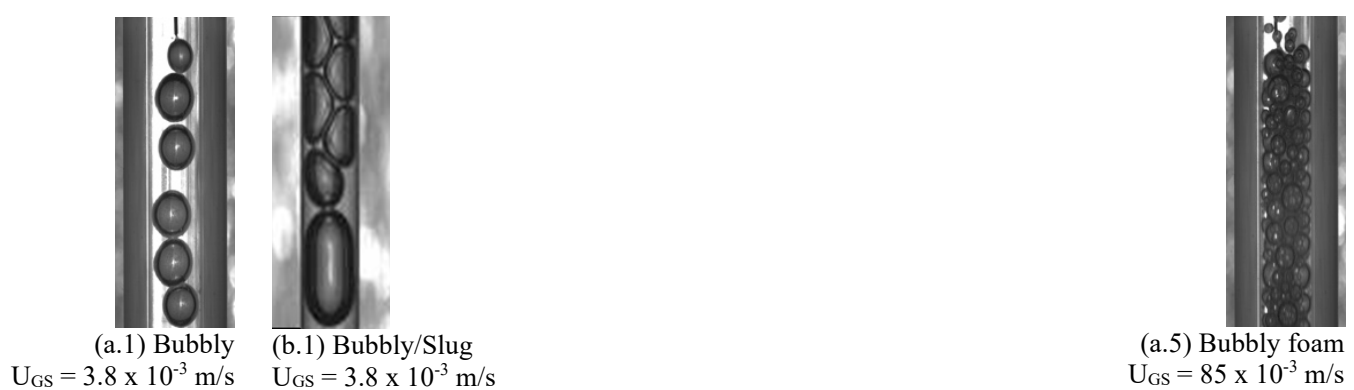

(a.5) Bubbly foam $\mathrm{U}_{\mathrm{GS}}=85 \times 10^{-3} \mathrm{~m} / \mathrm{s}$

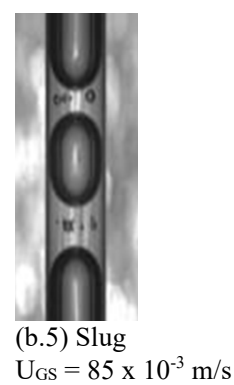

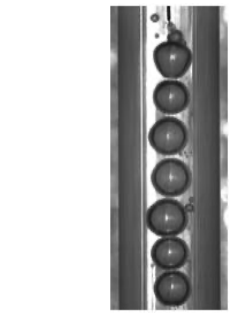

(a.2) Bubbly $\mathrm{U}_{\mathrm{GS}}=25 \times 10^{-3} \mathrm{~m} / \mathrm{s}$
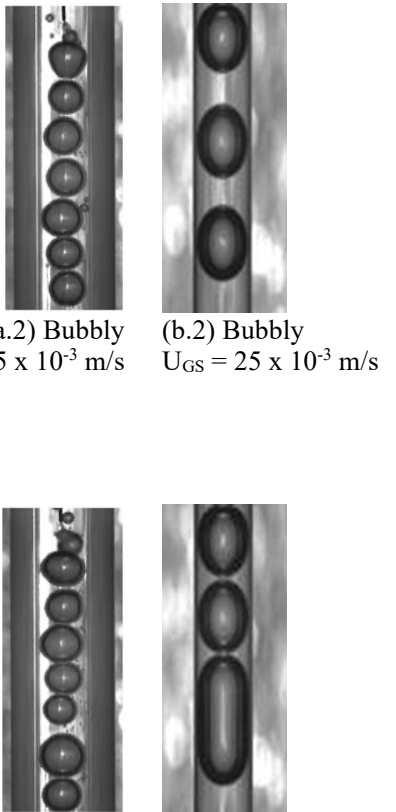

(a.3) Bubbly $\mathrm{U}_{\mathrm{GS}}=38 \times 10^{-3} \mathrm{~m} / \mathrm{s}$

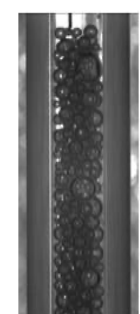

(a.4) Bubbly foam $\mathrm{U}_{\mathrm{GS}}=71 \times 10^{-3} \mathrm{~m} / \mathrm{s}$

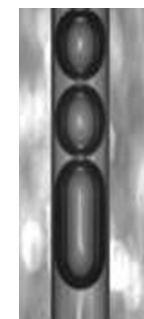

(b.3) Bubbly/slug $\mathrm{U}_{\mathrm{GS}}=38 \times 10^{-3} \mathrm{~m} / \mathrm{s}$

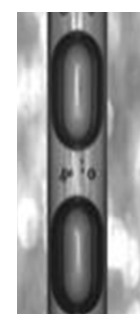

(b.4) Slug $\mathrm{U}_{\mathrm{GS}}=71 \times 10^{-3} \mathrm{~m} / \mathrm{s}$

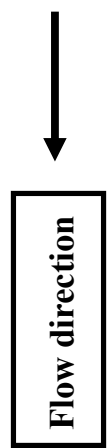

(a.6) Bubbly foam/slug $\mathrm{U}_{\mathrm{GS}}=90 \times 10^{-3} \mathrm{~m} / \mathrm{s}$

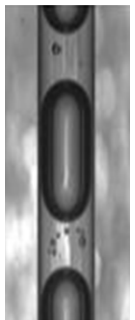

(b.6) Slug $\mathrm{U}_{\mathrm{GS}}=90 \times 10^{-3} \mathrm{~m} / \mathrm{s}$
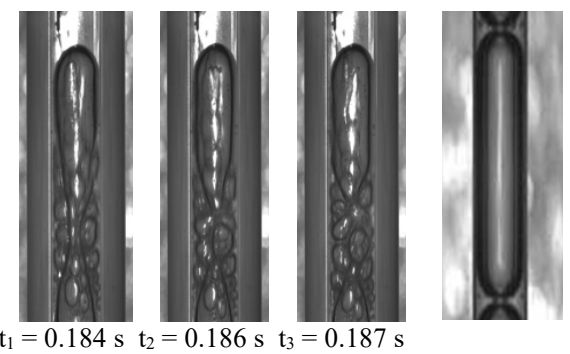

(a.7) Unstable annular $\mathrm{U}_{\mathrm{GS}}=156 \times 10^{-3} \mathrm{~m} / \mathrm{s}$

(b.7) Slug/annular $\mathrm{U}_{\mathrm{GS}}=156 \times 10^{-3} \mathrm{~m} / \mathrm{s}$
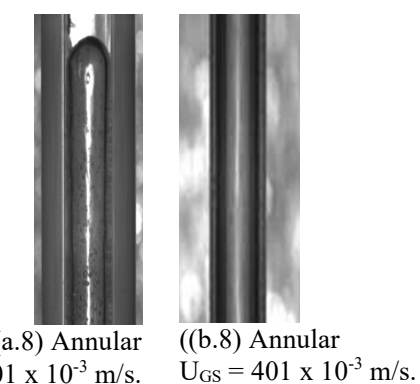

Fig.10: Typical patterns observed at (a) $L / D=10$ and (b) $L / D=420$ for downward flow and high liquid superficial velocity, $U_{L S}=59 \times 10^{-3} \mathrm{~m} / \mathrm{s}$. 


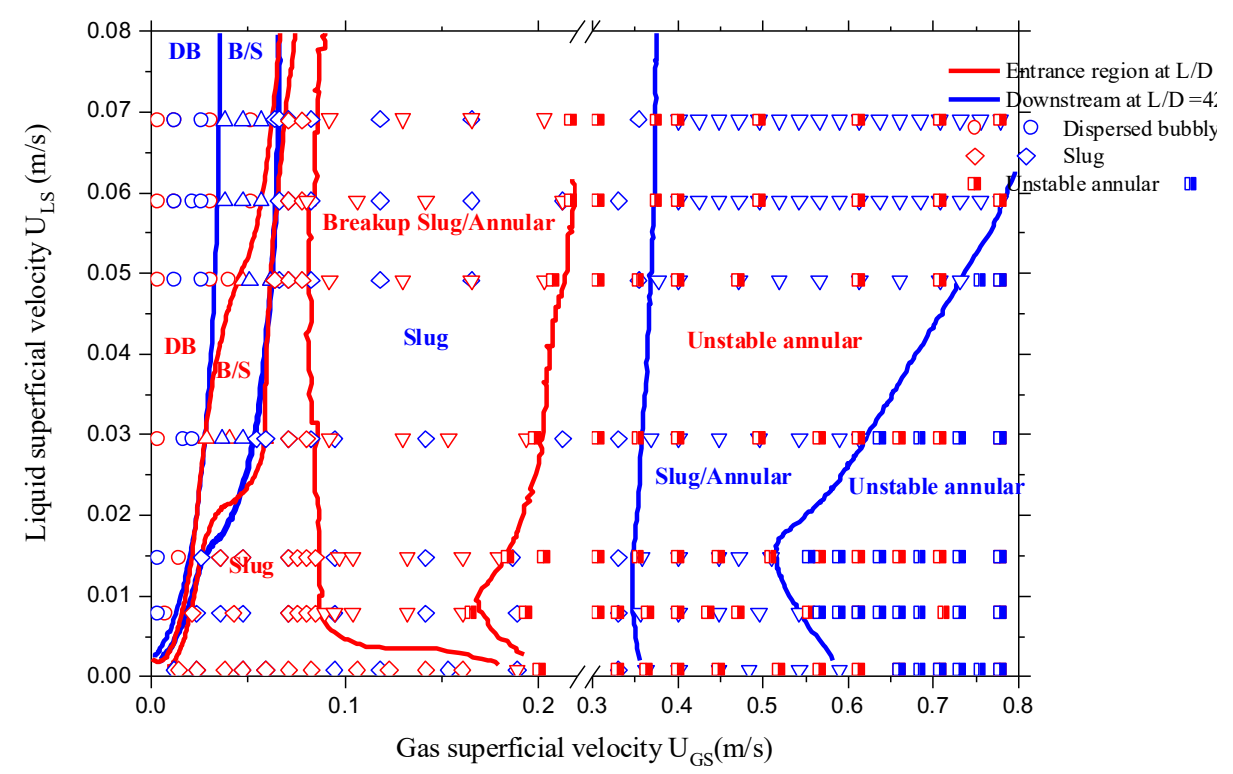

(a) map zoomed

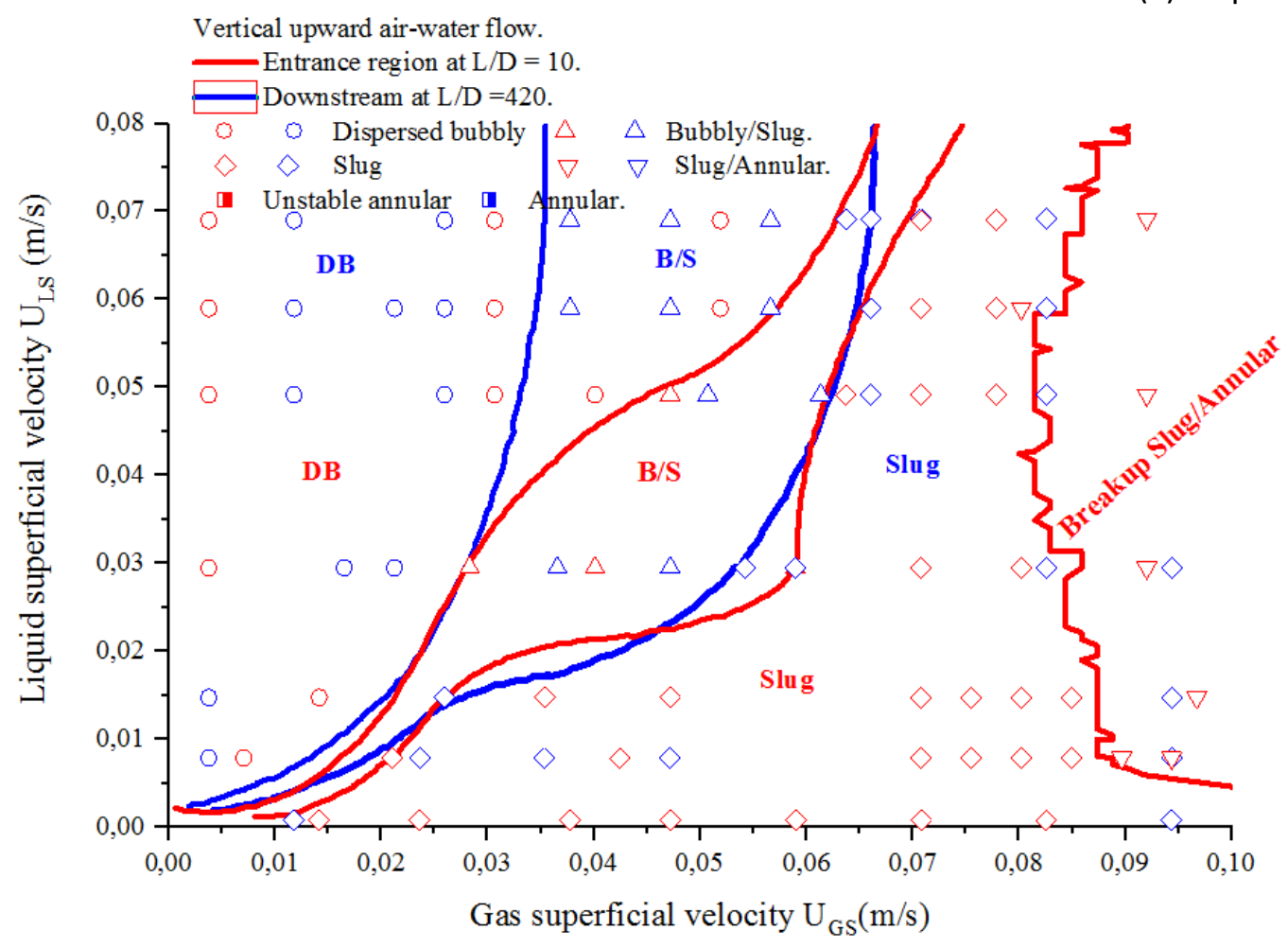

(b) zoom on the range of $0<U_{G S}<0.1 \mathrm{~m} / \mathrm{s}$

Fig. 11: Two-phase flow map of air water in a tube of $3 \mathrm{~mm}$ diameter for vertical upward orientation with respect to gravity at $\mathrm{L} / \mathrm{D}=10$ and at $\mathrm{L} / \mathrm{D}=420$. 

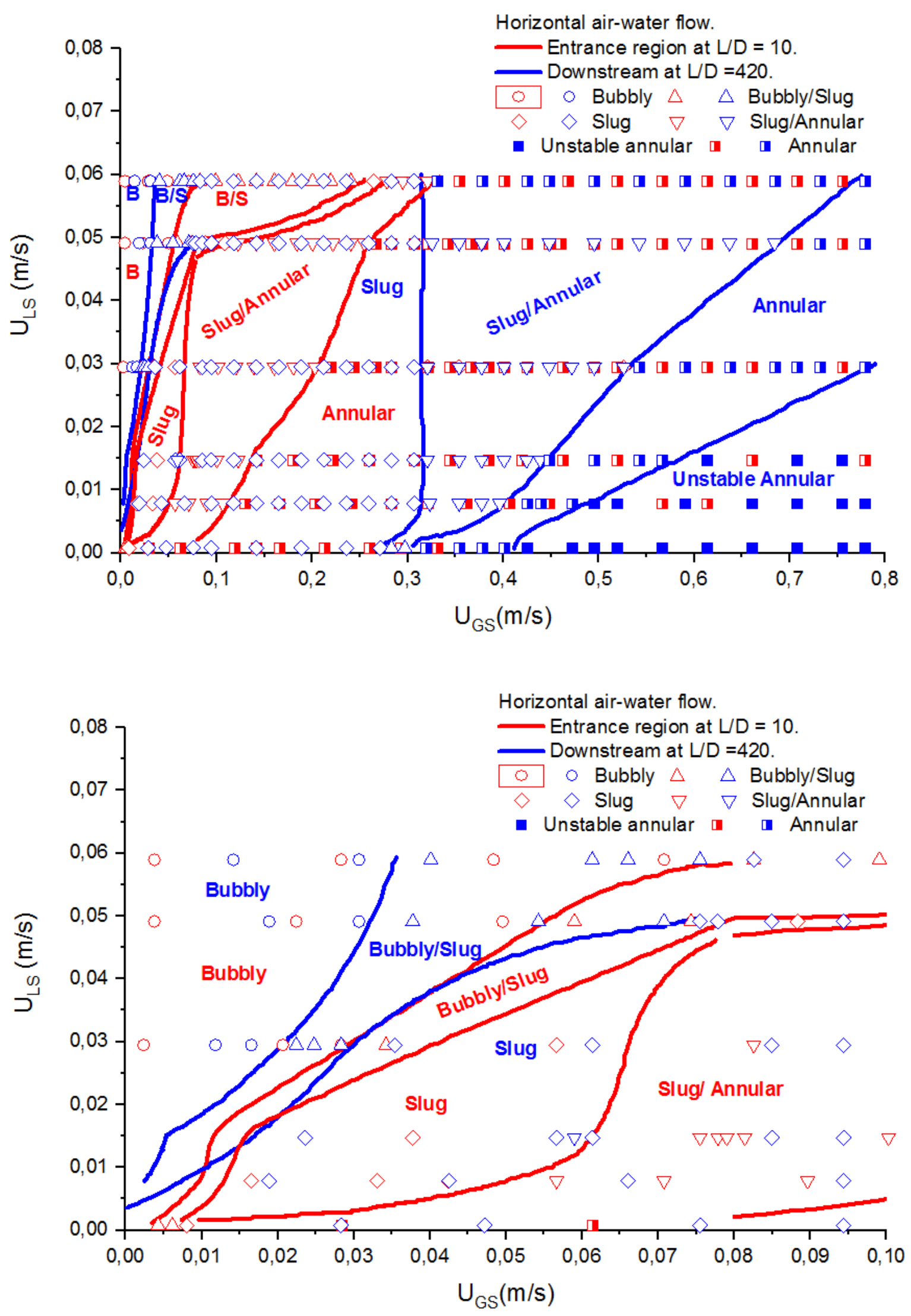

Fig. 12: Two-phase flow map of air water in a tube of $3 \mathrm{~mm}$ diameter for horizontal tube orientation with respect to gravity at $\mathrm{L} / \mathrm{D}=10$ and at $\mathrm{L} / \mathrm{D}=420$. 

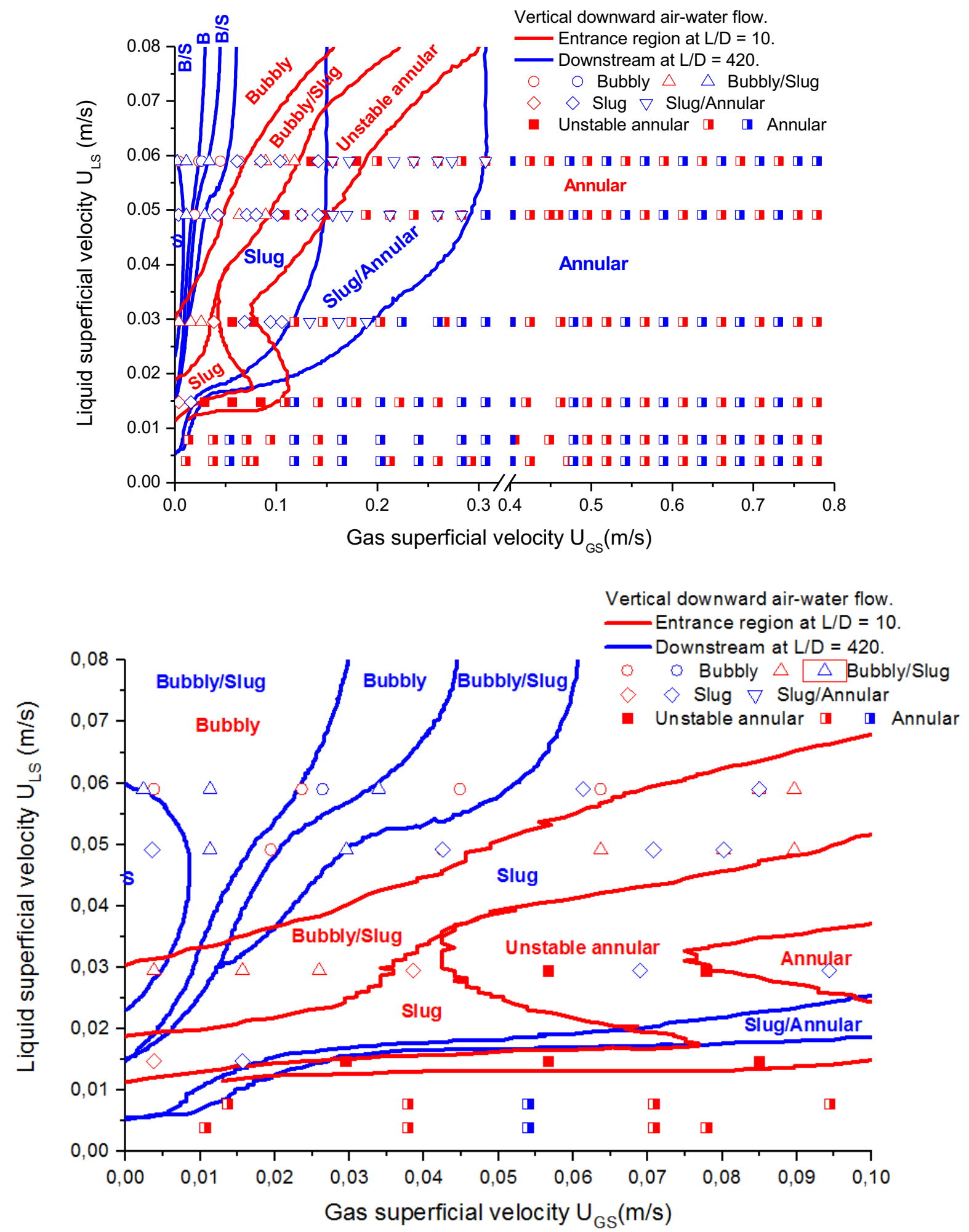

Fig. 13: Two-phase flow map of air water in a tube of $3 \mathrm{~mm}$ diameter for vertical downward orientation with respect to gravity at $\mathrm{L} / \mathrm{D}=10$ and at $\mathrm{L} / \mathrm{D}=420$. 

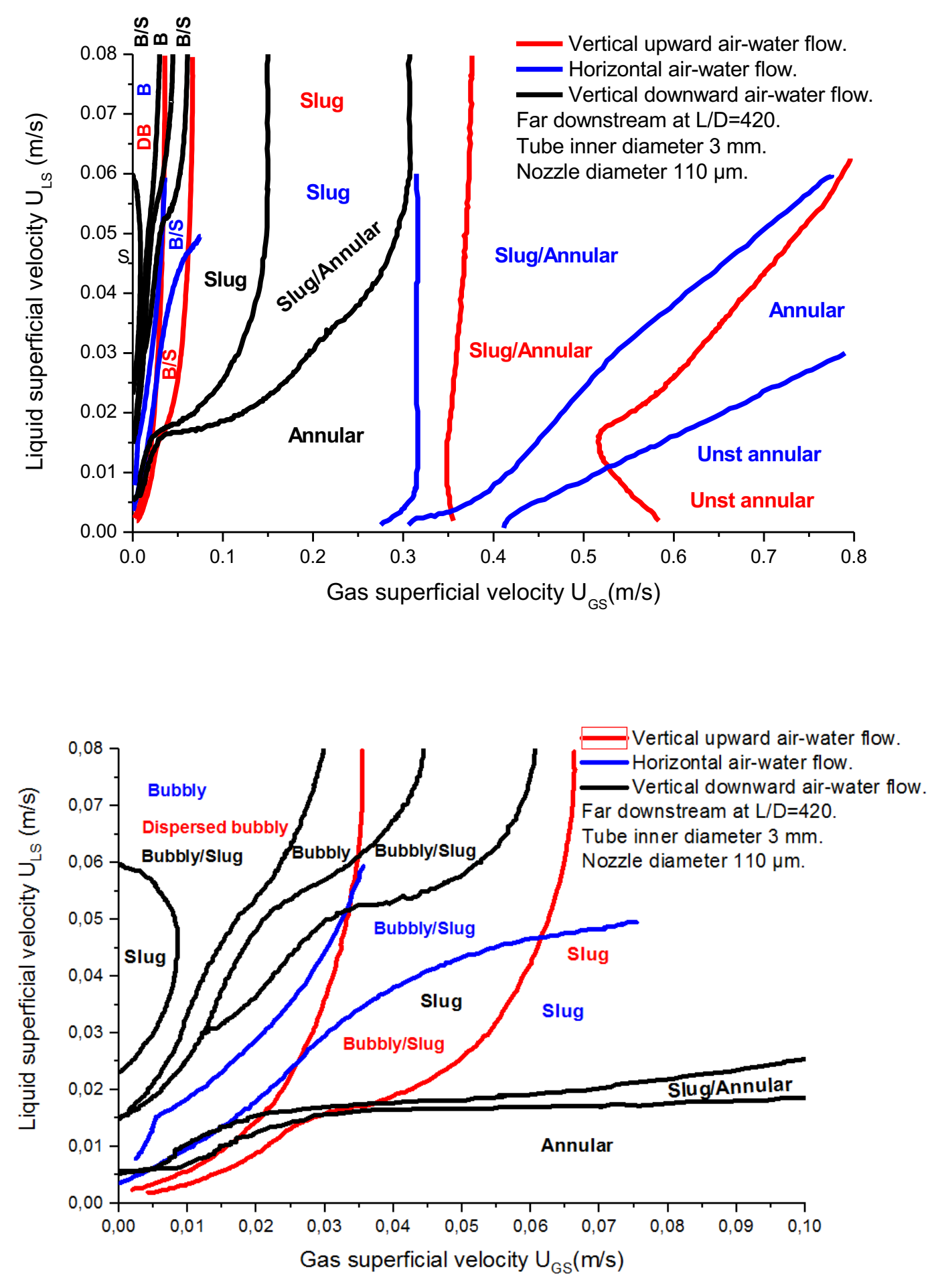

Fig.14: Two-phase flow map of air water in a tube of $3 \mathrm{~mm}$ diameter: Comparison between two-phase flow maps for vertical upward, horizontal, and vertical downward orientations with respect to gravity, at $\mathrm{L} / \mathrm{D}=420$. 
Table 1: Inventory of experimental works on air-water upward flow

\begin{tabular}{|c|c|c|c|}
\hline Authors & $\begin{array}{c}\text { Mixer } \\
\text { configuration }\end{array}$ & Test tube* and operating conditions & Flow patterns \\
\hline Barnea et al., 1983 & $\begin{array}{l}\text { not mentioned } \\
\text { in paper }\end{array}$ & $\begin{array}{l}\text { Upward, } \\
\text { glass, } d=4 \mathrm{~mm}, \\
\mathrm{U}_{\mathrm{GS}}=0.09-28.92 \mathrm{~m} / \mathrm{s} \\
\mathrm{U}_{\mathrm{LS}}=0.026-2.49 \mathrm{~m} / \mathrm{s}\end{array}$ & Slug, annular and dispersed \\
\hline Kariyasaki et al., 1992 & & $\begin{array}{l}\text { Upward, } \\
\text { Acrylic glass } ; \mathrm{d}=1,2.4,4.9 \mathrm{~mm} ; \\
\mathrm{U}_{\mathrm{GS}}=0.079-11.4 \mathrm{~m} / \mathrm{s} \\
\mathrm{U}_{\mathrm{LS}}=0.1-2 \mathrm{~m} / \mathrm{s}\end{array}$ & $\begin{array}{l}\text { Bubbly, intermittent, } \\
\text { annular. }\end{array}$ \\
\hline $\begin{array}{c}\text { Fukano and Kariyasaki, } \\
1993\end{array}$ & $\underset{\text { Water }}{\stackrel{\text { Air }}{\longrightarrow}}$ & $\begin{array}{l}\text { Upward and Downward, } \\
\text { Acrylic glass, } \mathrm{d}=1,2.4,4.9 \text { and } 26 \mathrm{~mm} \\
\mathrm{U}_{\mathrm{GS}}=0.1-30 \mathrm{~m} / \mathrm{s} \\
\mathrm{U}_{\mathrm{LS}}=0.02-2 \mathrm{~m} / \mathrm{s}\end{array}$ & $\begin{array}{l}\text { Bubbly, intermittent, } \\
\text { annular. }\end{array}$ \\
\hline Ide et al., 2007 & & $\begin{array}{l}\text { Horizontal, Upward and Downward, } \\
\text { glass circular ; d }=1,2.4 \text { and } 4.9 \mathrm{~mm} \text {; } \\
\text { rectangular, aspect ratio } 1-9 \\
\mathrm{U}_{\mathrm{GS}}=0.1-30 \mathrm{~m} / \mathrm{s} ; \mathrm{U}_{\mathrm{LS}}=0.03-2.3 \mathrm{~m} / \mathrm{s} \text {. }\end{array}$ & $\begin{array}{l}\text { Bubbly, Taylor (slug and } \\
\text { bubble-train slug), churn, } \\
\text { annular. }\end{array}$ \\
\hline Mishima et al., 1996 & $\|\left._{\text {Water }}\right|_{\downarrow}$ & $\begin{array}{l}\text { Upward, } \\
\text { Pyrex glass } ; \mathrm{d}=1-4 \mathrm{~mm} ; \\
\text { air nozzle } \mathrm{OD}=0.5 \mathrm{~mm} \\
\mathrm{U}_{\mathrm{GS}}=0.1-50 \mathrm{~m} / \mathrm{s} \\
\mathrm{U}_{\mathrm{LS}}=0.02-2 \mathrm{~m} / \mathrm{s}\end{array}$ & $\begin{array}{l}\text { Bubbly, Taylor, churn, } \\
\text { annular and dispersed } \\
\text { (annular mist) }\end{array}$ \\
\hline Wölk et al., 2000 & W Water & $\begin{array}{l}\text { Upward, } \\
\text { Transparent PMMA ; d = 5.9mm } \\
\text { UGS }=0.15-5 \mathrm{~m} / \mathrm{s} ; \mathrm{ULS}=0.36-4 \mathrm{~m} / \mathrm{s}\end{array}$ & $\begin{array}{l}\text { Dispersed bubbly, slug and } \\
\text { churn. }\end{array}$ \\
\hline
\end{tabular}


Table 2: Inventory of experimental works on air-water downward flow

\begin{tabular}{|c|c|c|c|}
\hline Autors & $\begin{array}{c}\text { mixer } \\
\text { configuration }\end{array}$ & Test tube* and operating conditions & Flow patterns \\
\hline $\begin{array}{l}\text { Biswas and Greenfield, } \\
1985\end{array}$ & $\underbrace{\downarrow}_{\text {Air/Water }} \downarrow^{g}$ & $\begin{array}{l}\text { Downward, } \\
\text { glass, } \mathrm{d}=0.5-7.1 \mathrm{~mm}, \\
\mathrm{U}_{\mathrm{GS}}=0.01-10 \mathrm{~m} / \mathrm{s} \\
\mathrm{U}_{\mathrm{LS}}=0.01-1 \mathrm{~m} / \mathrm{s}\end{array}$ & $\begin{array}{l}\text { Slug, stratified, annular and } \\
\text { dispersed }\end{array}$ \\
\hline $\begin{array}{l}\text { Galbiati and Andreini, } \\
1992\end{array}$ & 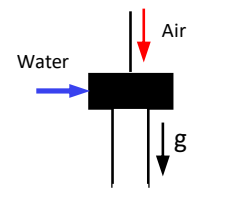 & $\begin{array}{l}\text { Downward, } \\
\text { glass, } \mathrm{d}=0.5,2 \mathrm{~mm}, \\
\mathrm{U}_{\mathrm{GS}}=0.01-10 \mathrm{~m} / \mathrm{s} \\
\mathrm{U}_{\mathrm{LS}}=0.001-1 \mathrm{~m} / \mathrm{s}\end{array}$ & Slug, annular. \\
\hline Kim et al., 2004 & $\left|\begin{array}{c}\text { Water } \\
\downarrow \\
\text { Air }\end{array}\right|$ & $\begin{array}{l}\text { Downward, } \\
\text { glass, } \mathrm{d}=25.4,50.8 \mathrm{~mm} \text {, } \\
\mathrm{U}_{\mathrm{GS}}=0.01-10 \mathrm{~m} / \mathrm{s} \\
\mathrm{U}_{\mathrm{LS}}=0.001-1 \mathrm{~m} / \mathrm{s}\end{array}$ & $\begin{array}{l}\text { Bubbly, slug, churn } \\
\text { turbulent, annular. }\end{array}$ \\
\hline Milan et al., 2013 & $\downarrow^{g}$ & $\begin{array}{l}\text { Downward, } \\
\text { glass, } \mathrm{d}=8.8 \mathrm{~mm}, \\
\mathrm{U}_{\mathrm{GS}}=0.05-2.35 \mathrm{~m} / \mathrm{s} \\
\mathrm{U}_{\mathrm{LS}}=0.03-0.42 \mathrm{~m} / \mathrm{s} .\end{array}$ & Bubbly, slug, annular. \\
\hline
\end{tabular}

* H: Horizontal, VU: Vertical Upward, VD: Vertical Downward

Test tube

Calming chamber 